\title{
Estimating the Upper Limit of Gas Production From Class 2 Hydrate Accumulations in the Permafrost: \\ 2. Alternative Well Designs and Sensitivity Analysis
}

\author{
George J. Moridis ${ }^{*}$ and Matthew T. Reagan \\ Lawrence Berkeley National Laboratory \\ 1 Cyclotron Rd., Berkeley, CA 94610
}

*Corresponding author: GJMoridis@lbl.gov, (510) 486-4746.

\begin{abstract}
In the second paper of this series, we evaluate two additional well designs for production from permafrostassociated (PA) hydrate deposits. Both designs are within the capabilities of conventional technology. We determine that large volumes of gas can be produced at high rates (several MMSCFD) for long times using either well design. The production approach involves initial fluid withdrawal from the water zone underneath the hydrate-bearing layer (HBL). The production process follows a cyclical pattern, with each cycle composed of two stages: a long stage (months to years) of increasing gas production and decreasing water production, and a short stage (days to weeks) that involves destruction of the secondary hydrate (mainly though warm water injection) that evolves during the first stage, and is followed by a reduction in the fluid withdrawal rate. A well configuration with completion throughout the HBL leads to high production rates, but also the creation of a secondary hydrate barrier around the well that needs to be destroyed regularly by water injection. However, a configuration that initially involves heating of the outer surface of the wellbore and later continuous injection of warm water at low rates (Case C) appears to deliver optimum performance over the period it takes for the exhaustion the hydrate deposit. Using Case C as the standard, we determine that gas production from PA hydrate deposits increases with the fluid withdrawal rate, the initial hydrate saturation and temperature, and with the formation permeability.
\end{abstract}

Keywords: methane hydrates, permafrost, production

\section{Introduction}

\subsection{Background}

In the first paper of this series (Moridis and Reagan, this issue) we provided an overall description of the various classes of hydrate deposits in geologic media, a synopsis of the methods for gas production from such 
deposits, and a discussion of the particular issues related to gas production from permafrost-associated (PA) hydrate deposits. Additionally, we discussed the numerical simulation approach, the discretization of the simulated domain, the properties of the various subdomains involved in the simulated system, and the initial and boundary conditions. Finally, we estimated production using as a base case (Case A) a conventional vertical well design, involving a 5-m-long production interval that was located fully within the water zone, beginning at the base of the Hydrate-Bearing Layer (HBL).

\subsection{Objectives}

In the second paper of this series, we investigate two additional cases of gas production from PA hydrate deposits that involve different vertical well designs. Case B employs wells with a long production interval, and Case $\mathrm{C}$ involves wells that have a variable production interval and outer wellbore heating (unavailable to Cases $\mathrm{A}$ and $\mathrm{B})$. We evaluate the relative performance of the different well designs in the three production cases for gas production from PA hydrate deposits. Additionally, we determine the sensitivity of gas production to important parameters: the initial mass production rate $\left(Q_{M 0}\right)$, and the initial hydrate saturation $\left(S_{H 0}\right)$.

Note that, as in the first part of this study (Moridis and Reagan, this issue), we concentrate on estimating the upper limit of production. Thus, our study follows standard production practices as long as possible earlier in the production period, but deviates from them (i.e., by operating the well at the highest - but time-variable production rates that could be sustained by the system, even after the well pressure reaches a level sufficiently low to warrant switching to production at a constant bottomhole pressure under standard field operating conditions) later in the production process. Moreover, our study does not address geomechanical considerations that can limit production.

\section{The Alternative Well Designs}

We investigated the production performance of two alternative well designs described by Moridis and Reagan (2007a), and compared it to that in the base case (Case A) analyzed in Moridis and Reagan (this issue). These designs involved different production intervals and operational procedures, and are both within current technological capabilities. As in Case A, the initial mass rate of fluid production from the vertical well in Cases 
$\mathrm{B}$ and $\mathrm{C}$ was $Q_{M 0}=9.2 \mathrm{~kg} / \mathrm{s}(=5,000 \mathrm{BPD}$ of water). The system properties and conditions are as in Table $1 \mathrm{of}$ Moridis and Reagan (this issue). The domain discretization, the approach and the simulation specifics are the same as in Moridis and Reagan (this issue).

\subsection{Case B: Long production interval}

In Case B, the production interval is unheated, covers the entire thickness of the HBL, and extends an additional $5 \mathrm{~m}$ into the WZ. This simple design involves conventional technology, and is initially equivalent to that in Case A because the effective permeability $k_{\text {eff }}$ in the HBL is extremely low. However, the active production interval becomes progressively larger and $k_{\text {eff }}$ in the HBL next to the well increases as hydrate dissociation advances. Thus, this well design promotes the evolution of a cylindrical interface of hydrate dissociation around the well in addition to the horizontal dissociation interface at the bottom of the hydrate interval (which advances upward). Other significant advantages of the well configuration in Case B were expected to include the access it provides to the upper dissociating interface (and the gas that accumulates at this location), and the ability of the system to automatically allocate and seamlessly shift production to the most favorable part of the well, as dictated by phase mobilities and thermodynamics. This is important if secondary hydrate and/or ice are formed near the well.

For a given mass production rate $\left(Q_{M}\right)$, the significantly larger production interval, coupled with the expanded area of dissociation, was expected to result in correspondingly milder pressure drops and a lower gas velocity (after gas emerges) in the vicinity of the well. This was in turn expected to lead to a reduction in the rate of cooling around the wellbore because of (a) the reduced rate of the endothermic dissociation reaction (caused by the milder pressure drop) and (b) the lessening of Joule-Thompson cooling (a consequence of the lower gas velocities). There was an expectation that higher $T$ could delay, slow, and/or possibly prevent the formation of secondary hydrate around the well, and also prolong the production time between cavitations.

However, the analysis of production from marine Class 2 deposits yielded results that were not consistent with these expectations, because rapid secondary hydrate formation caused well choking that did not allow long-term production (Moridis and Reagan, 2007a). Although this appears counterintuitive, it has a rational basis: it is attributed to the release of large amounts of gas by the rapidly dissociating warmer oceanic hydrates 
(about $7{ }^{\circ} \mathrm{C}$ warmer than the permafrost deposit in the current study), and the corresponding rapid cooling within the hydrate zone. The combination of large amounts of gas with low $T$ in the vicinity of the wellbore lead to the rapid hydrate reconstitution and flow blockage.

\subsection{Case C: Variable production interval with outer wellbore heating}

Case $\mathrm{C}$ involves a well that is initially similar to the one in Case A (with the perforated interval extending $5 \mathrm{~m}$ into the WZ), from which it differs in that the outer wellbore surface is heated (Figure 1). This heating causes thermal dissociation of the hydrate next to the well and leads to the creation of a zone of high $k_{\text {eff }}$ in the HBL and a cylindrical dissociation interface around the well. Electrical heating may be used (at least initially) if the $S_{H}$ of the undisturbed HBL is sufficiently high to make flow difficult. Because of superior heat transfer performance, warm water injection (injected at the upper part of the wellbore) was used at later times during production from oceanic Class 2 deposits (Moridis and Reagan, 2007a). Electrical heating, augmented with localized water injection near the HBL base (where secondary hydrates are likely to reconstitute) may be a better option in PA hydrates because it does not burden the lower $Q_{M}$ with a water injection that will inevitably affect adversely gas production (Figure 2).

The outer wellbore heating in this well design prevents the formation of secondary hydrate around the wellbore, and can provide a continuous flow pathway from both the cylindrical and the evolving upper horizontal dissociation interfaces to the perforated interval (Moridis and Reagan, 2007a). Such access is by no means guaranteed in the unheated Case B (in which it can be blocked by secondary hydrate formation), and very unlikely in Case A. The expectation is that fluid withdrawal using this well design will result in maximum gas release and production by maximizing the total dissociation area and access to the three interfaces (i.e., the cylindrical, the upper and the lower horizontal ones). As the cylindrical and the lower horizontal dissociation interfaces continue to recede during dissociation, it is possible to expand the production interval upward into the HBL (from its initial upper limit at the base of the hydrate zone) and reap the benefits of a longer perforated interval.

The well may be further modified at a later stage (usually when less than $40 \%$ of the original hydrate remains) when there is significant gas accumulation at the top of the reservoir. Despite high $S_{G}$ and large 
volumes, this gas cannot be recovered by using a conventional well perforated at the top of the formation because, after an initial short, high-rate, production period (lasting from hours to weeks), the well is blocked by secondary hydrate and ice (Moridis and Reagan, 2007a). The problem is alleviated by modifying the well according to the design of Figure 3, which involves alternating thin zones (about $1 \mathrm{~m}$ ) of gas production and warm water injection. The warm water is injected at a low rate $(<1 \mathrm{~kg} / \mathrm{s})$ at a relatively low $T$ (the reservoir is already cold because this well configuration is applicable only to an advanced stage of dissociation), and either prevents the formation of secondary hydrate or ice through mixing with the incoming fluid stream, or destroys pre-existing hydrate and ice blockages by thermal stimulation.

\section{System Response During Production in Case B}

\subsection{Gas and Water Production}

Figure 4 shows the evolution of $Q_{R}, Q_{P}$ and $Q_{a v g}$ in Case B. Figure 5 shows the corresponding $Q_{W}$ and $M_{W}$, in addition to the $Q_{M}$ imposed at the well. The evolution of $Q_{R}$ and $Q_{P}$ is similar in patterns to those from Case A (See Figure 4, Moridis and Reagan, this issue). We only have three production cycles (defined as the interval between the cavitation events that are evident in Figure 4). During each of the first two cycles, $Q_{R}$ and $Q_{P}$ increase rapidly monotonically, while the corresponding $Q_{w}$ decreases continuously (Figure 5).

Unlike Case A, warm water injection is necessary to destroy the secondary hydrate accumulation around the wellbore at the end of the first two production periods. Thus, production in Case B proceeds in cycles, each of which has two stages: an initial long stage (lasting months to years) of continuous production concluded by cavitation, followed by a short stage of destruction of the secondary hydrate or ice blocking flow by injecting warm water. The spike in $Q_{P}$ at the beginning of the third production cycle occurs when the secondary hydrate destruction provides access to the gas accumulated at the top of the formation. $Q_{R}$ is initially roughly stable in the third cycle, until a jump at about $t=3,300$ days caused by the $P$ dropping below the quadruple point level. This leads to rapid dissociation of the remaining hydrate, until its exhaustion at $t=3,950$ days.

$Q_{W}$ is initially almost equal to $Q_{M}$, but represents a progressively diminishing portion of $Q_{M}$ as time advances because of the increasing contribution of gas to the production stream until the depletion of the 
hydrate (Figure 5). $Q_{w}$ is initially constant in the third cycle, but begins to increase as the hydrate is exhausted and the water released from dissociation reaches the well (Figure 5).

Compared to Case A, the longer perforation interval allows exhaustion in a substantially shorter time $(4,500$ vs 6,480 days in Case A), leading to the $Q_{a v g}$ shown in Figure 7 . At $t=3,950$ days, $Q_{a v g}=1.46 \mathrm{ST} \mathrm{m} / \mathrm{s}(=4.44$ MMSCFD), i.e., substantially higher than that in Case A. The maximum $Q_{P}$ attained during production is $Q_{P}=$ 2.6 $\mathrm{ST} \mathrm{m}^{3} / \mathrm{s}$ (=8 MMSCFD) is also significantly higher than that observed in the base Case A, and its occurrence is followed by a long period during which $Q_{P}=2.15 \mathrm{ST} \mathrm{m} / \mathrm{s}(=6.56 \mathrm{MMSCFD})$. When $Q_{P}$ consistently exceeds $Q_{R}$ in the $2^{\text {nd }}$ and $3^{\text {rd }}$ cycle, gas production is partially fed by the gas stored in the reservoir during earlier dissociation.

There are fundamental differences between the performance of the well design in Case B during production from PA accumulations and from oceanic deposits. Gas production from oceanic deposits past a certain point is not even possible because of rapid formation of massive secondary hydrates that choke the well (Moridis and Reagan, 2007a). Conversely, production from PA deposits proceeds smoothly, and leads to practically full recovery of the resource (Figure 6). The results in Figures 4 and 5 appear to demonstrate the superiority of the long wellbore design in Case B over that in Case A during production from Class 2 PA deposits.

Figure 6 shows the evolution of $V_{R}$ and $V_{P}$ in Case B. At the end of the simulation $(t=4,500$ days), the hydrate is exhausted (as indicated by the flat portion of the $V_{R}$ curve after $t=3,900$ days), and $V_{P}>0.98 V_{R}$ if production is not limited by geomechanical considerations, and if the well is operated at the variable $Q_{M}$ regime described above. During the 4,500 days of the simulation, the total of $V_{P}=5.56 \times 10^{8} \mathrm{ST} \mathrm{m}^{3}\left(=1.96 \times 10^{10} \mathrm{ST} \mathrm{ft}^{3}\right)$ of $\mathrm{CH}_{4}$ that were produced defines the upper limit of production.

Note that the pseudo-porous medium approximation for the description of flow through the wellbore (see Section 3.4, Moridis and Reagan, this issue) does not pose any problems to the simulation of the warm water injection process needed to destroy the secondary hydrate. Following the cessation of production, a constant injection rate of warm water is applied to the top of the well, and the phase redistribution caused by the injection is easily handled by the system. 


\subsection{Spatial Distributions of Important Variables in Case B}

3.2.1 Spatial distributions of $S_{\boldsymbol{H}}$ and $S_{G}$. Figures 7 and 8 show the evolution of the $S_{H}$ and $S_{G}$ distributions over time near the wellbore $(r<20 \mathrm{~m})$. As in all cases of gas hydrates (Moridis et al., 2007; Moridis and Reagan, 2007a; Moridis and Reagan, 2007b), the process of gas production is controlled by the phenomena that occur within a short radius around the well, hence the focus on this narrow zone. The dissociation pattern is very different from that in Case A (see Figures 7 and 8, Moridis and Reagan, this issue), but the features that are common to both cases are (a) the evolution of the upper dissociation interface and of a conical interface around the well, and (b) the gas accumulation between the receding upper hydrate interface and the base of the overburden.

Dissociation begins at both the lower interface at the HBL base and at the emerging upper interface at the base of the overburden, in addition to around the well (Figures 7a and 8a). These figures depict the easy flow of gas from the cone-shaped dissociation front and the upper interface to the perforated interval, which now spans the entire thickness of the HBL and extends $5 \mathrm{~m}$ into the WZ. This dissociation pattern is a direct consequence of the well design, which also leads to the evolution of secondary hydrate structures that encircles the well (Figure 7a) in a manner akin to a glove. This structure becomes thicker over time as hydrate accumulates on its outer surface (Figures 7a, 7c and 7e). The finger-like appendix at the bottom of the structures appears to move away from the well as time advances because of hydrate dissociation along its inner surface (where depressurization is at its maximum) and accretion along its outer surface (where the temperature is low and free gas comes in contact with water). Destruction of the secondary hydrate structures requires less than 30 days and involves injection of $50{ }^{\circ} \mathrm{C}$ water (with a specific enthalpy of $H_{W}=2.50 \times 10^{5} \mathrm{~J} / \mathrm{kg}$ ) at a rate of $Q_{I}=1 \mathrm{~kg} / \mathrm{s}$ (Figures $8 \mathrm{~b}, 8 \mathrm{~d}$ and $8 \mathrm{f}$ ).

Continuing dissociation along the upper interface and gas rise due to buoyancy lead to the creation of high$S_{G}$ gas bank above the main body of the hydrate, i.e., between the receding upper interface and the base of the overburden (Figure 8c and beyond). The implications of this pattern (universal to all hydrate classes under depresssurization-induced production) are significant, and have already been discussed. The $S_{H}$ distribution in Figure $7 \mathrm{~h}$ shows the significant destruction of hydrate during the 3240-day production period. The injection of 
warm water can be easily seen in Figures $8 \mathrm{~b}, 8 \mathrm{~d}$ and $8 \mathrm{f}$, which show significant reductions in $S_{G}$ as the injected water expels the gas after destroying the secondary hydrate. Gas flow is easily restored when production resumes.

An interesting feature is the difference in appearance and location of the secondary hydrate barriers that develop during production: while barriers in Class 2 PA deposits are thick and are located immediately next to the wellbore, the barriers in oceanic deposits are thin, move away from the well, and are stabilized at a considerable distance (Moridis and Reagan, 2007a).

3.2.2 Spatial distributions of $\boldsymbol{T}$. The $T$ distribution in Figure 9 indicates continuous cooling in the deposit as dissociation and production proceeds, and conforms to expectations. The effect of the barrier is obvious, indicating dissociation of the inner surface of the secondary hydrate structure (Figures 7a, 7c and 7e), in addition to Joule-Thompson cooling at the same locations. The presence of the injected warm water is evident in Figures 9b, 9d and 9f, and the intense cooling because of depressurization around the well is evident in Figures 9a, 9c and 9e. Note that the temperature in the body of the remaining hydrate at $\mathrm{t}=3240$ days is $\mathrm{T} \leq 2$ ${ }^{\circ} \mathrm{C}$ (compared to over $13{ }^{\circ} \mathrm{C}$ at the initiation of production).

\section{System Response During Production in Case C}

\subsection{Gas and Water Production}

In Case C, electrical heat was initially applied to the outer surface of the wellbore at a rate of $Q_{Q}=200 \mathrm{~W} / \mathrm{m}$ (see Figure 3). Figure 10 shows the evolution of $Q_{R}, Q_{P}$ and $Q_{a v g}$ in Case C. Despite drastically different well designs, both $Q_{R}$ and $Q_{P}$ are remarkably similar in pattern and values to those from Cases B (Figure 7) during the first production cycle for the reasons explained earlier. An additional reason is that all three create roughly the same hydrate-free zone (and, consequently, a cylindrical or conical dissociation interface and a fast flow pathway) around the well, albeit by different means: Cases A and B by pure depressurization, while Case $\mathrm{C}$ by a combination of depressurization and thermal stimulation.

What is very different in Case $\mathrm{C}$ (as will be clearly shown later) is that secondary hydrate formation is minimal (to non-existent), and all but one of the several cavitation events that are evident at the end of each 
production cycle in Figure 10 (denoted by the subsequent drops in $Q_{P}$ and $Q_{R}$, as dictated by the need to reduce $Q_{M}$ ) are not caused by flow obstruction by secondary hydrate formation, but by the continuous replacement of the denser water by the lower-density gas in the production stream. Warm water (at a rate $Q_{I}=1 \mathrm{~kg} / \mathrm{s}$ and an enthalpy of $H_{W}=2.75 \times 10^{5} \mathrm{~J} / \mathrm{kg}$ ) was injected at the bottom of the HBL to destroy the limited amount of secondary hydrate after the first cavitation event. No more secondary hydrate was observed after that time. At the end of the first cycle, the well configuration of Figure 2 (Stage 2) was implemented, with electrical heating ceasing and warm water (at $Q_{I}=0.25 \mathrm{~kg} / \mathrm{s}$ and $H_{W}=2.6 \times 10^{5} \mathrm{~J} / \mathrm{kg}$ ) injected immediately above the top of the production interval. The well configuration of Figure 3 (Stage 3) was implemented at the beginning of the $4^{\text {th }}$ cycle (beginning at about $t=2,550$ days), with warm water injected at 18 locations along the entire initial thickness of the HBL at a steadily declining cumulative $Q_{I}$ (from $0.2 \mathrm{~kg} / \mathrm{s}$ to $0.1 \mathrm{~kg} / \mathrm{s}$ ) and $H_{W}=2.6 \times 10^{5} \mathrm{~J} / \mathrm{kg}$. Thus, only the first of the production cycles in Case $\mathrm{C}$ includes a separate warm water injection stage without concurrent production. All other cycles involve continuous production with concurrent injection of limited amounts of warm water, punctuated by a simple $Q_{M}$ reduction after each cavitation event.

After the first cavitation event, we increased the production interval by perforating an additional $2 \mathrm{~m}$ of wellbore into the HBL. This was possible because dissociation had turned the area around the wellbore at this location into a hydrate-free zone, and lead to an increase in $Q_{P}$. Beginning in the second production cycle, $Q_{P}$ consistently exceeded $Q_{R}$, indicating that gas production was partially supported by the gas stored earlier in the reservoir.

Figure 11 shows $Q_{W}$ and $M_{W}$, in addition to the $Q_{M}$ imposed at the well. The patterns are analogous to those described in Case B, but the number of production cycles (and the corresponding reductions in $Q_{W}$ ) are larger than in Cases A and B. $Q_{W}$ declines monotonically and consistently in every production cycle, as increasing amounts of gas reach the well. As Figure 12 shows, at the end of the 3850-day simulation period, a total of $V_{P}=$ $5.56 \times 10^{8} \mathrm{ST} \mathrm{m}^{3}\left(=1.96 \times 10^{10} \mathrm{ST}^{3}\right)$ have been produced, i.e., the hydrate is totally exhausted and the $\mathrm{CH}_{4}$ practically fully recovered. From Figure 10, the corresponding average gas production $Q_{a v g}=1.66 \mathrm{ST} \mathrm{m} / \mathrm{s}(=$ 5.06 MMSCFD), and is the highest of all three cases. 
The results in Figures 10 to 12 demonstrate the clear superiority of the wellbore design in Case $\mathrm{C}$ over those in Cases A and B. Although the difference in performance between cases B and C is not very large, the avoidance of the evolution of possibly unpredictable hydrate barriers in close proximity to the well (Figure 7) during gas production represents a significant advantage. Note that Case $\mathrm{C}$ is the only case of significant similarity of the well performance in PA and in oceanic deposits (Moridis and Reagan, 2007).

Note that the pseudo-porous medium approximation for the description of flow through the wellbore (see Section 3.4, Moridis and Reagan, this issue) does not pose any problems to the simulation of the warm water injection process proceeding concurrently with production. A constant $Q_{M}$ is applied to the top of the wellbore (simulating production through the tubing), while the warm water injection occurs into the appropriate gridblocks next to the wellbore (representing injection through the perforated casing).

\subsection{Spatial Distributions of Important Variables in Case C}

4.2.1 Spatial distributions of $\boldsymbol{S}_{\boldsymbol{H}}, \boldsymbol{S}_{\boldsymbol{G}}$ and $\boldsymbol{S}_{\boldsymbol{I}}$. Figures 13 and 14 show the evolution of the $S_{H}$ and $S_{G}$ spatial distributions in the critical narrow zone $(r<20 \mathrm{~m})$ around the wellbore. The dissociation pattern is different from that in Cases A (see Figure 7 in Moridis and Reagan, this issue) and B (Figure 12), but the universal features of hydrate dissociation persist. These include (a) the evolution of the upper dissociation interface and of a cylindrical interface around the well, and (b) the accumulation of gas above the receding upper hydrate interface under the overburden.

Dissociation begins at both the lower interface at the HBL base and at the cylindrical interface around the well, and then proceeds along the evolving upper dissociation interface (Figures 13 and 14). These figures confirm the intended objective of the design, i.e., to maintain easy access to the gas from all dissociation fronts to the well (see Figures 1 to 3). The resulting dissociation pattern is a direct consequence of the well design. Its most important feature is the practical absence of secondary hydrates, which are formed in significant quantity only during the first production cycle (Figure 13b), and then never reappear. This is attributed to the continuous heating (initially electrical and later through warm water injection) along the outer surface of the wellbore. The 
$S_{H}$ distribution in Figure 13d shows the significant destruction of hydrate as early as 1,916 days into the 3,850day production period.

Figure 14 shows the accumulation of gas below the base of the overburden because of continuing dissociation and buoyancy-driven gas rise to the top of the formation. A significant gas bank is also observed below the hydrate body (Figures 14d and 14f). The injection of warm water can be easily deduced from the $S_{G}$ distribution in Figure 14c (first production cycle). The location of the warm water injection next to the wellbore is identifiable as a low $S_{G}$ region.

Of particular interest is the ice saturation $S_{I}$ distribution in Figure 15. Ice evolves late, i.e., during the fourth production cycle, when the $Q_{M}$ rate is sufficiently high to induce freezing and $S_{G}$ is sufficiently high to avoid gas permeability limitations as the aqueous phase is replaced by an expanding solid ice phase. After the exhaustion of the hydrate at $t=3,380$ days, the ice body shrinks because of continuous heat influx from the boundaries and the cessation of the dissociation.

4.2.2 Spatial distributions of $\boldsymbol{T}$. The $T$ distribution in Figure 16 clearly shows the continuous reservoir cooling expected during hydrate dissociation, as well as the effects of electrical heating and warm water injection. The flow of colder water released from dissociation to the well can be easily discerned.

\section{Sensitivity Analysis}

The sensitivity analysis focused on Case $\mathrm{C}$ because of the superiority of the corresponding well design. We investigated the sensitivity of gas production to (a) the initial mass production rate $Q_{M 0}$, (b) the initial hydrate saturation $S_{H O}$, (c) the intrinsic permeability $k$ of the $\mathrm{HBL}$ and the WZ, and (d) the initial temperature $T_{0}$ of the HBL.

\subsection{Sensitivity to $Q_{M 0}$}

Figure 17 shows the evolution of $Q_{R}$ and $Q_{P}$ when $Q_{M 0}=2 Q_{M 0, r e f}$, where $Q_{M 0 \text {, ref }}$ is the $Q_{M 0}$ in the reference Case C. Comparison of Figures 17 and 10 indicates the maximum $Q_{P}$ exceeds that in the reference Case $\mathrm{C}$, the same $V_{P}$ is produced over a significantly lower period, and, consequently, the corresponding $Q_{a v g}=2.02 \mathrm{ST} \mathrm{m} / \mathrm{s}(=$ 
6.17 MMSCFD) is significantly higher. However, because of the inability to maintain a constant $Q_{M}$ during the entire course of production, the increase in $Q_{a v g}$ is sub-linear. The obvious conclusion is that gas production is favored by an increasing $Q_{M 0}$, and the largest possible $Q_{M 0}$ should be applied initially.

\subsection{Sensitivity to $S_{H 0}$}

Figure 18 shows the dependence of $Q_{P}$ on $S_{H 0}$. A lower $S_{H 0}$ leads to a lower $Q_{P}$ because the higher initial $k_{\text {eff }}$ (and, consequently, the faster depressurization and hydrate dissociation) are outweighed by the reduction in the resource. Thus, $Q_{P}$ is consistently lower (albeit slightly) when $S_{H 0}=0.55$ than in the reference case, in which $S_{H 0}=0.7$ (see Table 1 in Moridis and Reagan, this issue). This is the opposite to the response of deeper, warmer oceanic hydrates (Moridis and Reagan, 2007a), in which $Q_{P}$ increases with a decreasing $S_{H 0}$.

\subsection{Sensitivity to $k$}

Figure 19 shows the dependence of $Q_{R}$ and $Q_{P}$ on $k$. The results from the standard Case C (Figure 10) are compared to those obtained from a system with the same well configuration, properties and conditions, but with $k=k_{r e f} / 2$ and $k=k_{r e f} / 5$, where $k_{r e f}$ is the value reported in Table 1 of Moridis and Reagan (this issue). As expected, a lower $k$ leads to lower $Q_{R}$ and $Q_{P}$ for a long time (longer than 10 years) because of less effective (and limited in extent) depressurization and hydrate dissociation. This is consistent with observations in deeper, warmer oceanic hydrates (Moridis and Reagan, 2007a).

\subsection{Sensitivity to $T_{0}$}

Figure 20 shows the dependence of $Q_{R}$ and $Q_{P}$ on the initial reservoir temperature $T_{0}$ for a given pressure distribution (equal to that shown in Figure 3 of Moridis and Reagan, this issue). The results from the standard Case C (Figure 10) are compared to those obtained from a system with the same well configuration, properties and conditions, but with $T_{0}=T_{0, r e f}-3$ and $T_{0}=T_{0, r e f}-5$, where $T_{0, r e f}$ is the initial $T$-distribution shown in Figure 3 of Moridis and Reagan (this issue). As expected, a lower $T$ leads to lower $Q_{R}$ and $Q_{P}$ for a long time (almost 3,000 days) because of a smaller "sensible heat reservoir" available to sustain the depressurization-induced 
dissociation. The more complicated situation for $t>3,000$ days is a result of slightly different heating regime in the vicinity of the wellbore, and not a systemic trend.

\section{Other Important Observations}

\subsection{Uniformity of system response away from the well}

As previously indicated (Moridis and Reagan 2007a;b), processes and phenomena that occur within a narrow zone around the well control gas production from the entire hydrate deposit. This critical zone has a limited radius $r_{c}$ (usually $<10-15 \mathrm{~m}$ ), and fine discretization must be used for its simulation if these near-well phenomena are to be captured and accurately described. Dissociation and flow patterns are uniform and smooth for $r>r_{c}$. Figures 7, 13, and 14, as well as Figure 7 in Moridis and Reagan (this issue) indicate that this is the case during production from Class 2 PA hydrates. This confirms the general observation that hydrate deposits under depressurization-induced production dissociate uniformly along the entire area of their horizontal interfaces, a behavior that is caused by the very large $k_{\text {eff }}$ disparity between the HBL and its hydrate-free surroundings (Moridis and Reagan, 2007a; 2007b). This dissociation pattern is quite different from that observed in gas production from Class 1 hydrates (Moridis et al., 2007). The difference is attributed to the very different initial properties of the gas-rich Class 1 deposits (much lower thermal conductivity and larger specific heat, in addition to the substantial compressibility of the native gas phase), leading to faster cooling, localized processes and the emergence of substantially heterogeneous phase (including alternating bands of high and low $\left.S_{H}\right)$ and property distributions.

\subsection{Water-to-gas ratio}

When technology and equipment availability do not pose challenges, the technical and economic feasibility of a production method is generally evaluated by employing two criteria: (a) an absolute criterion of sufficiently high $Q_{P}$, and (b) a relative criterion of an acceptably low water-to-gas ratio, defined as $R_{W G C}=M_{W} / V_{P}$. The continuously and rapidly declining $R_{W G C}$ in Figure 21 confirms earlier observations (Moridis and Reagan, $2007 \mathrm{a} ; 2007 \mathrm{~b}$ ) that this is a universal feature of depressurization-based production from hydrate deposits. The 
decline in $R_{W G C}$ is reversed when the hydrate is exhausted. These observations are valid under any of the conditions and production methods investigated in this study. Hydrate deposits reserve their worst performance for the initial stages of production, but then they exhibit rapid and continuous improvement. This is in stark contrast to the production behavior in conventional gas reservoirs, in which $R_{W G C}$ almost invariably increases over time.

The $R_{W G C}$ of Case $\mathrm{C}$ in Figure 19 is lower than that of Case A and slightly so than that of case $\mathrm{B}$, further indicating the superiority of the corresponding well configuration. The lower $S_{H 0}$ results in a more desirable (lower) $R_{W G C}$ initially, although this later changes as the hydrate is exhausted. The general observation is that there are no glaring differences in the performance of these four cases in terms of water-to-gas ratio, as all of them have rather similar $R_{W G C}$. The case of $Q_{M 0}=2 Q_{M 0, \text { ref }}$ appears to be distinctly different, as the corresponding $R_{W G C}$ is consistently lower than that of the reference case during the entire course of production. This further underlines the desirability of a higher $Q_{M 0}$ as a production strategy. The shape and pattern of the $R_{W G C}$ curves are entirely analogous to those observed in production from oceanic hydrate deposits (Moridis and Reagan, 2007a), and appear to be characteristic of depressurization-based dissociation.

\section{Summary and Conclusions}

(1) In addition to the base case (Case A) well design studied in the first part of this series (Moridis and Reagan, this issue), we proposed two different well designs for gas production from Class 2 hydrate deposits in the permafrost. The production interval in the design of Case B is completed in the entire HBL and extends another 5m into the WZ. The last design (Case C) has the same configuration as Case A, but involves heating of the outer surface of the wellbore and may involve extensions of the production interval through additional perforations. All three designs involve conventional technology.

(2) We applied an initial mass withdrawal rate from the well $Q_{M 0}=9.2 \mathrm{~kg} / \mathrm{s}(=5,000 \mathrm{BPD})$. In all cases, gas from dissociation is released rapidly into the hydrate deposit. Gas production is characterized by a relatively short ( $<100$ days) lead period of low gas production, followed by a period of rapid $Q_{P}$ rise fueled by hydrate dissociation, and begins in earnest when $S_{G}$ exceeds the $S_{i r G}$ level. 
(3) $Q_{R}$ and $Q_{P}$ continue to increase until cavitation (characterized by rapid pressure drop at the well) occurs. The main reason for its occurrence is either the creation of a secondary hydrate structure (barrier) that blocks flow, or the replacement of the denser water by the lighter gas in the production stream at levels that cannot satisfy the imposed $Q_{M}$. Cavitation is treated by destroying the secondary gas hydrate barrier (if such a structure has formed during production) through warm water injection, and by reducing $Q_{M}$. A reduction in $Q_{M}$ does not necessarily translate into a reduction of $Q_{P}$.

(4) Production proceeds in cycles between cavitation events. The first stage of each cycle involves continuous gas production and is several hundred days long. The second stage is short (a few weeks if hydrate destruction is needed), and can even be very short (seconds to minutes) if only a reduction in $Q_{M}$ is needed to overcome cavitation. $Q_{P}$ continuously increases during the production stage of each cycle, with a corresponding reduction in $Q_{W}$.

(5) The results indicate that gas can be produced from hydrates at high rates using any of the three well designs when the HBL is bound by confining boundaries. Dissociation is characterized by features that are common to all deposits: (a) the evolution of an upper dissociation interface at the top of the hydrate layer (caused by heat flows from the upper boundary) in addition to the lower dissociation interface at the bottom of the HBL, and (b) gas accumulation below the base of the overburden because of continuing dissociation and buoyancy-driven gas rise to the top of the formation.

(6) Processes and phenomena that occur within a narrow zone around the well control gas production from the entire hydrate deposit. This critical zone has a radius $r_{c}<10-15 \mathrm{~m}$, and fine discretization must be used in its simulations if these near-well phenomena are to be accurately described. Dissociation and flow patterns are uniform and smooth along the entire area of the horizontal interfaces for $r>r_{c}$.

(7) In Case B, during the 4,500-day production period, a total of $V_{P}=5.56 \times 10^{8} \mathrm{ST} \mathrm{m}^{3}\left(=1.96 \times 10^{10} \mathrm{ST} \mathrm{\textrm {ft } ^ { 3 }}\right)$ of $\mathrm{CH}_{4}$ were produced at an average rate $Q_{\text {avg }}=1.46 \mathrm{ST} \mathrm{m}^{3} / \mathrm{s}(=4.44 \mathrm{MMSCFD})$. The well design in Case B allows access to upper dissociation interface and leads to the creation of a vertical dissociation interface around the well, but also leads to the creation of a secondary hydrate barrier around the well that needs to be destroyed regularly by water injection. 
(8) In Case C, during the 3,850-day production period, a total of $V_{P}=5.56 \times 10^{8} \mathrm{ST} \mathrm{m}^{3}\left(=1.96 \times 10^{10} \mathrm{ST} \mathrm{ft}^{3}\right)$ of $\mathrm{CH}_{4}$ were produced at an average rate $Q_{a v g}=1.66 \mathrm{ST} \mathrm{m}^{3} / \mathrm{s}(=5.06 \mathrm{MMSCFD})$. The well design in Case $\mathrm{C}$ allows access to upper dissociation interface, leads to the creation of a vertical dissociation interface around the well, and prevents the formation of secondary hydrate barriers around the well.

(9) Because of the production regime imposed at the well (which did not involve switching to production at a constant $P_{w}$ after pressure drops below a certain level), the production estimates in Cases B and C represent the upper limits of production from the PA hydrate deposit investigated here using the corresponding well configurations.

(10) The results of this study demonstrate the superiority of the wellbore design in Case C over those in Cases A and B in production from PA deposits.

(11) Using the well configuration of Case $\mathrm{C}$ as the standard, sensitivity analysis indicates that gas production increases with an increasing $Q_{M 0}$, an increasing $k$ and an increasing $T_{0}$. Unlike the case of deeper, warmer oceanic hydrates (Moridis and Reagan, 2007a), a decrease in $S_{H 0}$ does not lead to an increase in $Q_{P}$ that would be expected because of the lower initial $k_{\text {eff. }}$

(12) Contrary to conventional gas reservoirs, $R_{W G C}$ declines continuously and rapidly during depressurizationbased production from hydrates, following a characteristic pattern and indicating a continuously improving performance. The $R_{W G C}$ data confirm the superiority of the well design in Case C, and the desirability of applying the largest possible $Q_{M 0}$ for optimum production.

\section{Acknowledgments}

This work was supported by the Assistant Secretary for Fossil Energy, Office of Natural Gas and Petroleum Technology, through the National Energy Technology Laboratory, under the U.S. Department of Energy, Contract No. DE-AC02-05CH11231. The authors are indebted to Stefan Finsterle, John Apps, and Dan Hawkes for their thorough reviews. 


\section{References}

Moridis, G.J., Kowalsky, M.B., Pruess, K., 2007. "Depressurization-Induced Gas Production From Class 1 Hydrate Deposits," SPE Reservoir Evaluation \& Engineering, 10(5), 458-481.

Moridis, G.J., Reagan, M.T., 2007a. "Gas Production From Oceanic Class 2 Hydrate Accumulations,” OTC 18866, 2007 Offshore Technology Conference, Houston, Texas, U.S.A., 30 April-3 May 2007.

Moridis, G.J., Reagan, M.T., 2007b. "Strategies for Gas Production From Oceanic Class 3 Hydrate Accumulations," OTC 18865, 2007 Offshore Technology Conference, Houston, Texas, U.S.A., 30 April-3 May 2007.

Moridis, G.J., Reagan, M.T., 2010. "Estimating the Upper Limit of Gas Production From Class 2 Hydrate Accumulations in the Permafrost: 1. Concepts, System Description, and the Production Base Case," Journal of Petroleum Science and Engineering, XX(YY), ZZZZ (this issue).

\section{Nomenclature}

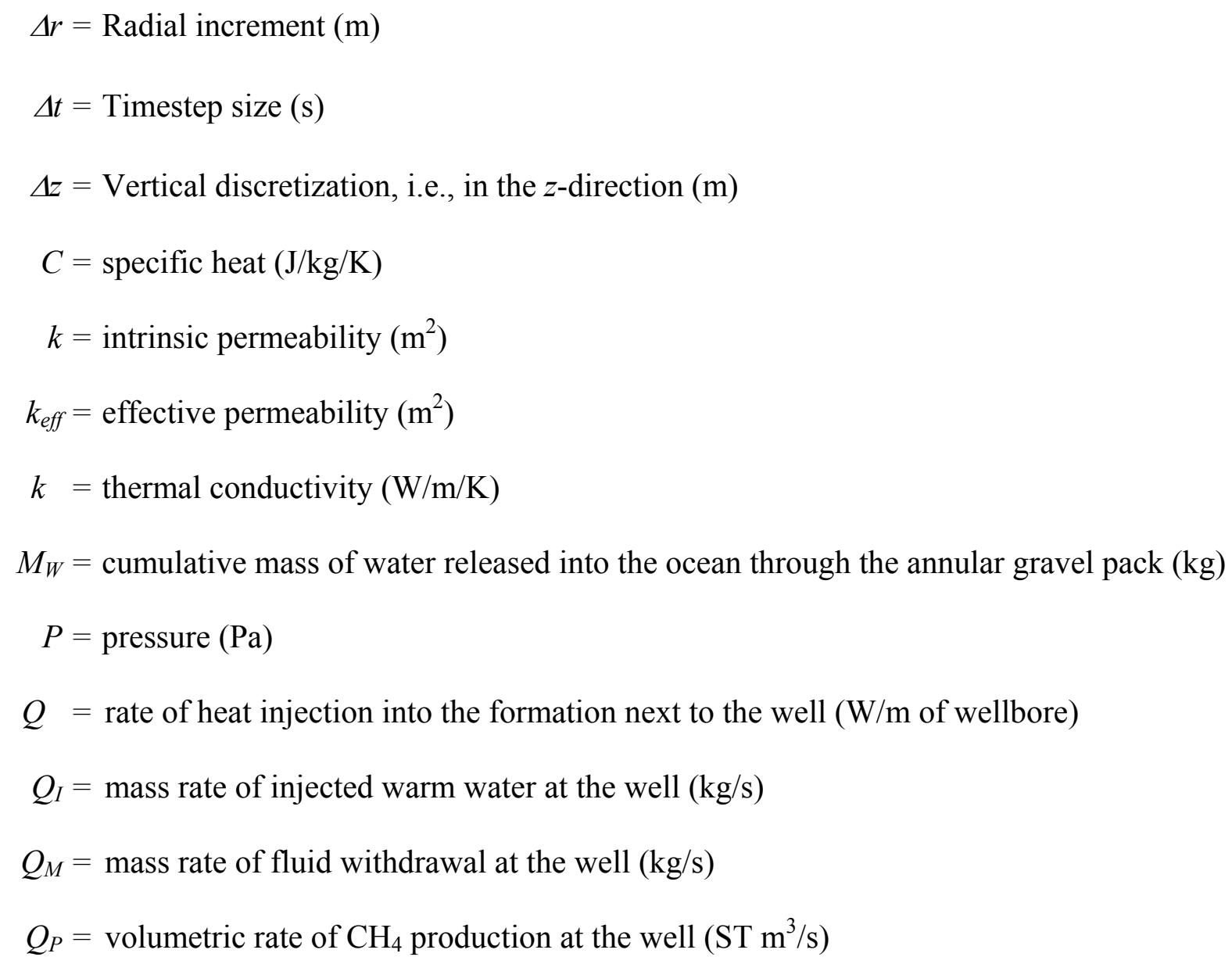


$Q_{R}=$ volumetric rate of $\mathrm{CH}_{4}$ release from hydrate dissociation into the reservoir $(\mathrm{ST} \mathrm{m} / \mathrm{s})$

$Q_{W}=$ mass rate of water release into the ocean through the annular gravel pack $(\mathrm{kg} / \mathrm{s})$

$Q_{R}=$ rate of $\mathrm{CH}_{4}$ release from hydrate dissociation $\left(\mathrm{ST} \mathrm{m}^{3} / \mathrm{s}\right)$

$r, z=$ coordinates $(\mathrm{m})$

$r_{c}=$ critical radius of maximum activity around the wellbore $(\mathrm{m})$

$r_{w}=$ well radius $(\mathrm{m})$

$r_{\max }=$ maximum radius of the simulation domain $(\mathrm{m})$

$R_{W G C}=$ cumulative water-to-gas ratio $\left(\mathrm{kg} / \mathrm{ST} \mathrm{\textrm {m } ^ { 3 } )}\right.$

$S=$ phase saturation

$t=$ time (days)

$T=$ temperature $\left(\mathrm{K}\right.$ or $\left.{ }^{\circ} \mathrm{C}\right)$

$V_{P}=$ cumulative volume of $\mathrm{CH}_{4}$ released into the ocean through the annular gravel pack $\left(\mathrm{ST} \mathrm{m}^{3}\right)$

$V_{R}=$ cumulative volume of $\mathrm{CH}_{4}$ released from hydrate dissociation $\left(\mathrm{ST} \mathrm{m}^{3}\right)$

\section{Greek Symbols}

$\lambda=$ van Genuchten exponent

$\phi=$ porosity

\section{Subscripts and Superscripts}

$$
\begin{aligned}
0 & =\text { denotes initial state } \\
A & =\text { aqueous phase } \\
e & =\text { equilibrium conditions } \\
\text { cap } & =\text { capillary } \\
G & =\text { gas phase } \\
G 0 & =\text { initial gas phase } \\
H & =\text { solid hydrate phase }
\end{aligned}
$$


$H O=$ initial solid hydrate phase

$$
P=\text { production stream }
$$

$r e f=$ reference Case $\mathrm{C}$

$$
R=\text { rock }
$$

$R=$ rock

$$
w=\text { well }
$$




\section{FIGURE CAPTIONS}

Figure 1 - Well design used in the initial production stages of Case C. The production interval begins at the HBL and extends into the WZ, while the outer surface of of the wellbore in contact with the HBL is heated.

Figure 2 - Well design variant used in the early and intermediate production stages of Case C. Warm water is injected into the formation near the top of the perforated interval.

Figure 3 - Well design used in the late stages of production in Case C. The system involves thin alternating zones of production and warm water injection.

Figure 4 - Rates of (a) hydrate-originating $\mathrm{CH}_{4}$ release in the reservoir $\left(Q_{R}\right)$ and (b) $\mathrm{CH}_{4}$ production at the well $\left(Q_{P}\right)$ during production from the Class 2 PA hydrate deposit in Case $B$. The evolution of the average gas production rate $\left(Q_{\text {avg }}\right)$ over the simulation period is also shown.

Figure 5 - (a) Mass rate of total fluid production, $Q_{M}$, (b) mass rate of $\mathrm{H}_{2} \mathrm{O}$ production, $Q_{w}$ and (b) cumulative mass of produced $\mathrm{H}_{2} \mathrm{O}$ ( $M_{W}$ ) during production from the Class 2 PA hydrate deposit in Case $B$.

Figure 6 - Cumulative volumes of (a) hydrate-originating $\mathrm{CH}_{4}$ released in the reservoir $\left(V_{R}\right)$ and $(b)$ produced $\mathrm{CH}_{4}$ at the well $\left(V_{P}\right)$ during production from the Class 2 PA hydrate deposit in Case $A$.

Figure 7 -Evolution of spatial distribution of $S_{H}$ during gas production from the Class 2 PA hydrate deposit in Case $B$.

Figure 8 -Evolution of spatial distribution of $S_{G}$ during gas production from the Class 2 PA hydrate deposit in Case B.

Figure 9 -Evolution of spatial distribution of T during gas production from the Class 2 PA hydrate deposit in Case B.

Figure 10 - Rates of (a) hydrate-originating $\mathrm{CH}_{4}$ release in the reservoir $\left(Q_{R}\right)$ and $(\mathrm{b}) \mathrm{CH}_{4}$ production at the well $\left(Q_{P}\right)$ during production from the Class 2 PA hydrate deposit in Case $C$. The evolution of the average gas production rate $\left(Q_{\text {avg }}\right)$ over the simulation period is also shown.

Figure 11 - (a) Mass rate of total fluid production, $Q_{M}$, (b) mass rate of $\mathrm{H}_{2} \mathrm{O}$ production, $Q_{w}$ and (b) cumulative mass of produced $\mathrm{H}_{2} \mathrm{O}\left(M_{W}\right)$ during production from the Class 2 PA hydrate deposit in Case $C$.

Figure 12 - Cumulative volumes of (a) hydrate-originating $\mathrm{CH}_{4}$ released in the reservoir $\left(V_{R}\right)$ and $(b)$ produced $\mathrm{CH}_{4}$ at the well $\left(V_{P}\right)$ during production from the Class 2 PA hydrate deposit in Case $\mathrm{C}$.

Figure 13 -Evolution of spatial distribution of $S_{H}$ during gas production from the Class 2 PA hydrate deposit in Case $C$.

Figure 14 -Evolution of spatial distribution of $\mathrm{S}_{\mathrm{G}}$ during gas production from the Class 2 PA hydrate deposit in Case $\mathrm{C}$.

Figure 15 -Evolution of spatial distribution of $S_{1}$ during gas production from the Class 2 PA hydrate deposit in Case C.

Figure 16 -Evolution of spatial distribution of T during gas production from the Class 2 PA hydrate deposit in Case C.

Figure 17 - Evolution of $Q_{R}$ and $Q_{P}$ during production from the Class 2 PA hydrate deposit in Case $C$ for $Q_{M 0}=2 Q_{M 0, r e f}$ The evolution of $Q_{M}$ and $Q_{\text {avg }}$ over the simulation period are also shown.

Figure $18-Q_{R}$ and $Q_{P}$ during production from the Class 2 PA hydrate deposit in Case C when $S_{H}=0.55\left(Q_{H}=9.2 \mathrm{~kg} / \mathrm{s}\right)$. The average production rate $\left(Q_{\text {avg }}\right)$ over the simulation period is also shown.

Figure 19 - Effect of $k$ on $Q_{R}$ and $Q_{P}$ during production from the Class 2 PA hydrate deposit in Case C $\left(Q_{H O}=9.2 \mathrm{~kg} / \mathrm{s}\right)$.

Figure 20 - Effect of $T_{0}$ on $Q_{R}$ and $Q_{P}$ during production from the Class 2 PA hydrate deposit in Case C $\left(Q_{H_{0}}=9.2 \mathrm{~kg} / \mathrm{s}\right)$.

Figure 21 - Evolution of the water-to-gas ratio $\left(\boldsymbol{R}_{w G c}\right)$ over time during gas production from the PA hydrate deposit in this study. Note the continuous and monotonic decline of $R_{W G C}$ until the time of the hydrate exhaustion. 


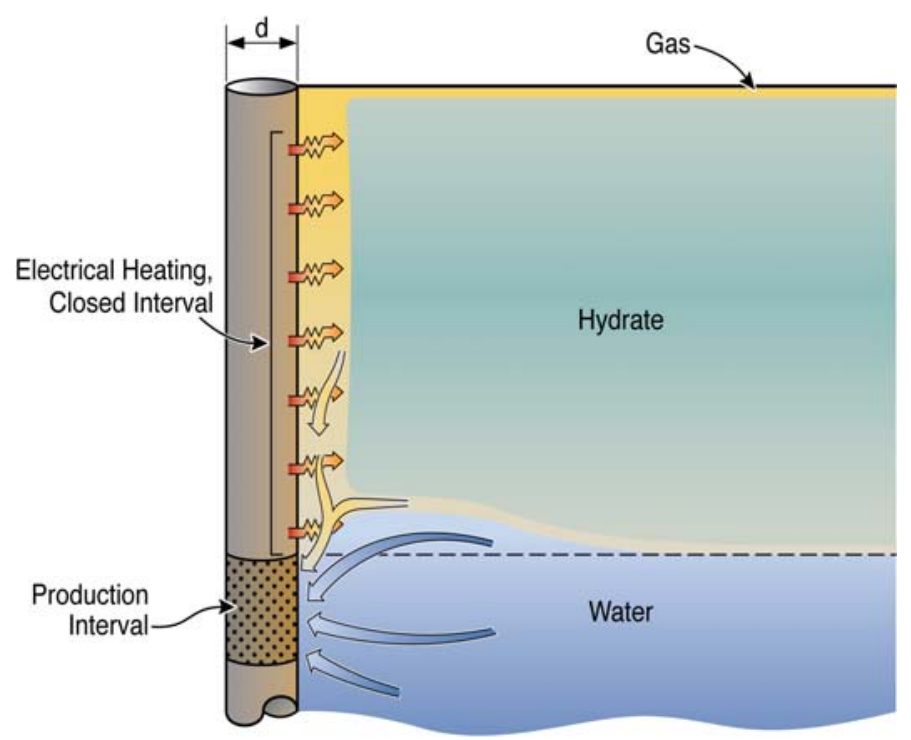

ESD07-014

Figure 1 - Well design used in the initial production stages of Case C. The production interval begins at the HBL and extends into the WZ, while the outer surface of the wellbore in contact with the HBL is heated.

Phase 2

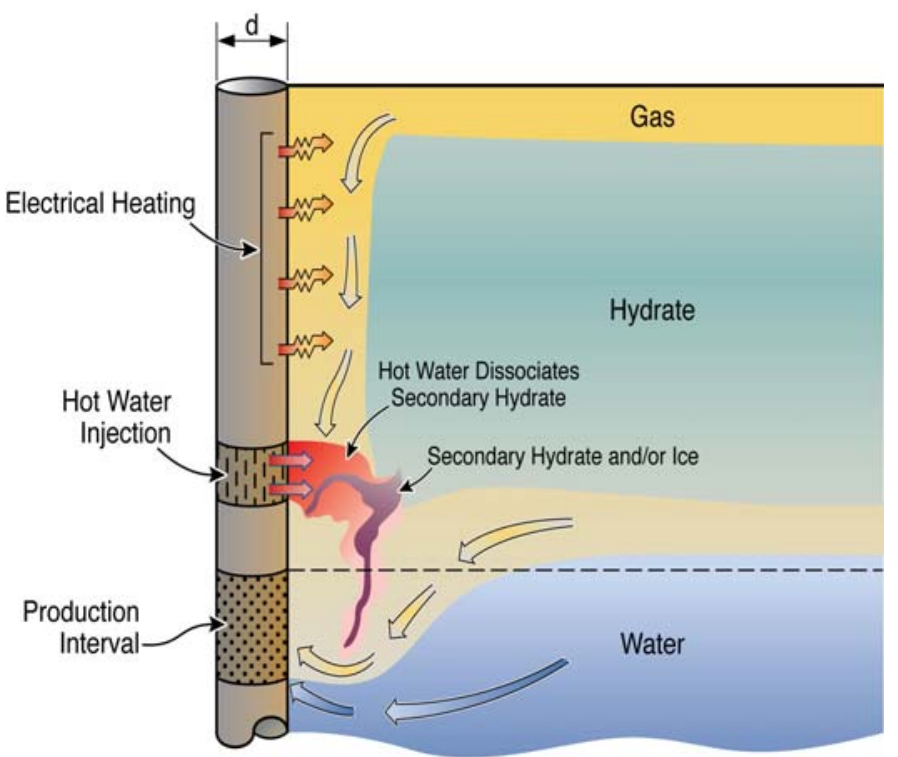

ESD07-00

Figure 2 - Well design variant used in the early and intermediate production stages of Case C. Warm water is injected into the formation near the top of the perforated interval. 
Phase 3

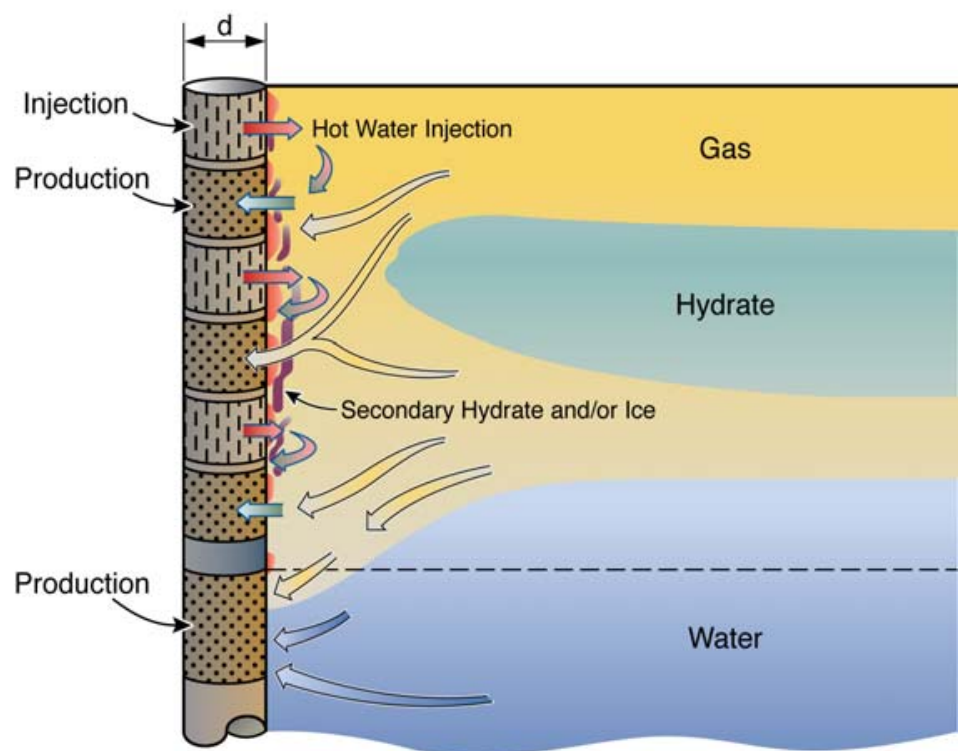

Figure 3 - Well design used in the late stages of production in Case C. The system involves thin alternating zones of production and warm water injection.

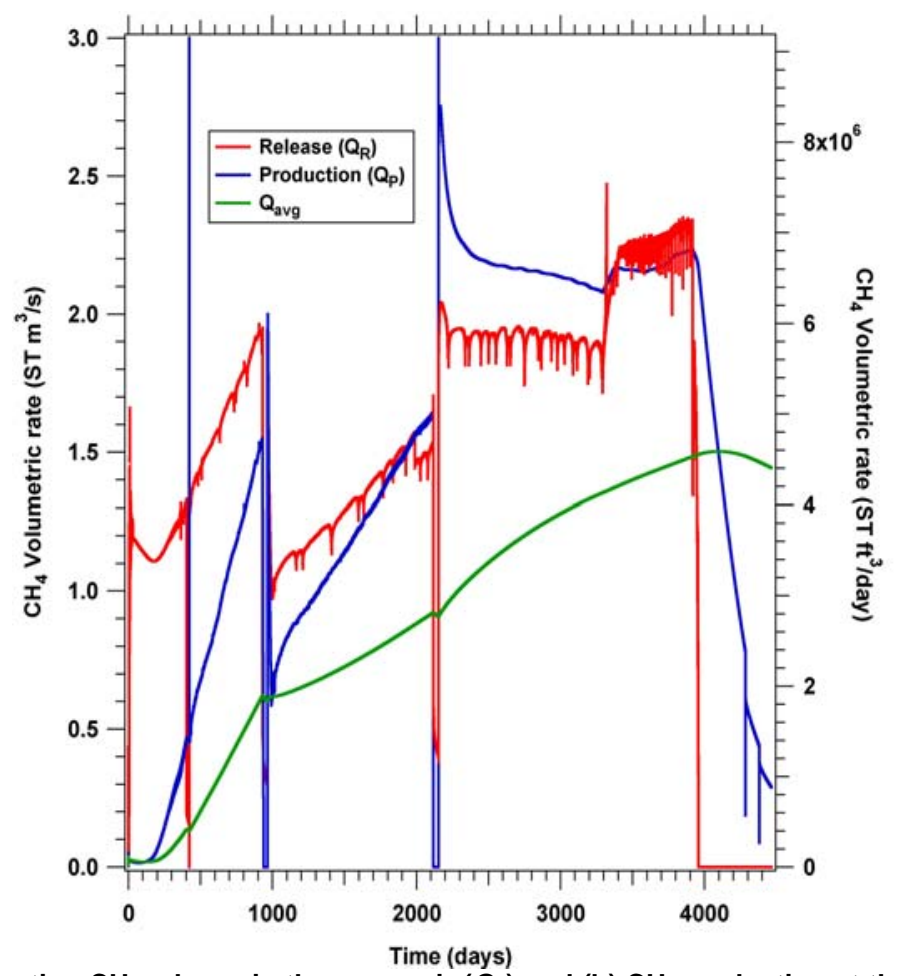

Figure 4 - Rates of (a) hydrate-originating $\mathrm{CH}_{4}$ release in the reservoir $\left(Q_{R}\right)$ and (b) $\mathrm{CH}_{4}$ production at the well $\left(Q_{P}\right)$ during production from the Class 2 PA hydrate deposit in Case B. The evolution of the average gas production rate $\left(Q_{\text {avg }}\right)$ over the simulation period is also shown. 


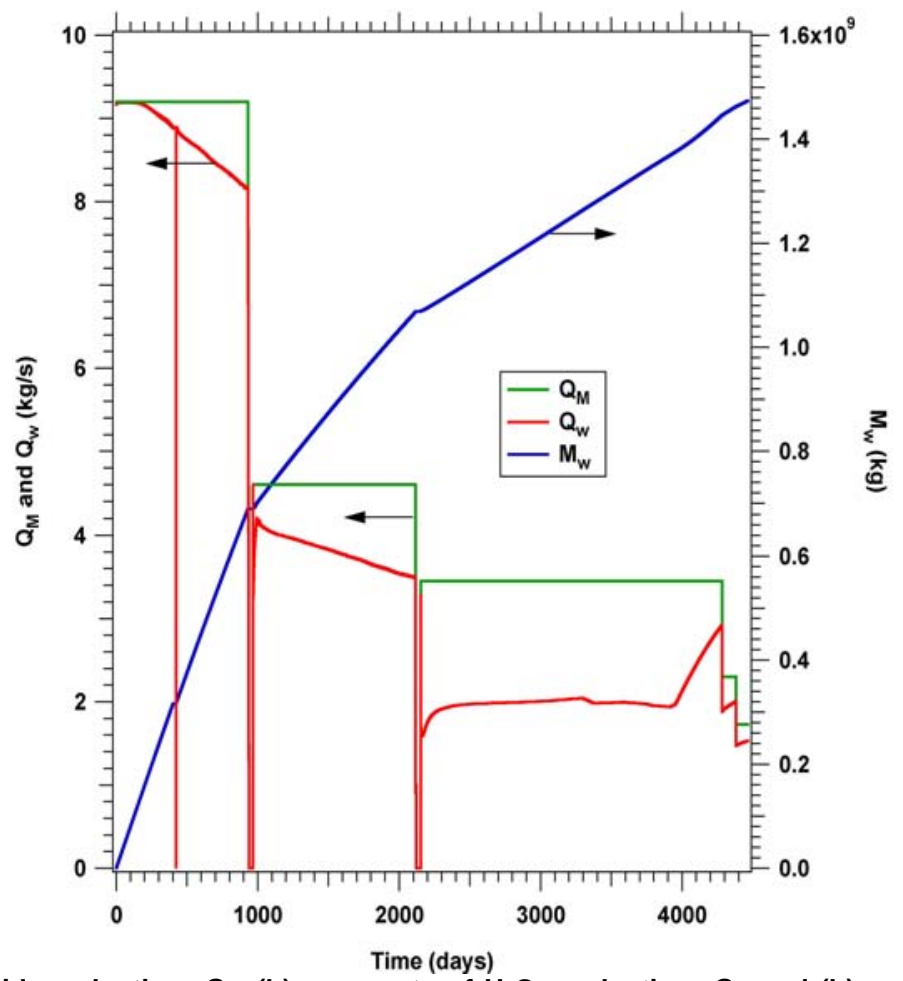

Figure 5 - (a) Mass rate of total fluid production, $Q_{M}$, (b) mass rate of $\mathrm{H}_{2} \mathrm{O}$ production, $Q_{w}$ and (b) cumulative mass of produced $\mathrm{H}_{2} \mathrm{O}$ ( $M_{W}$ ) during production from the Class 2 PA hydrate deposit in Case B.

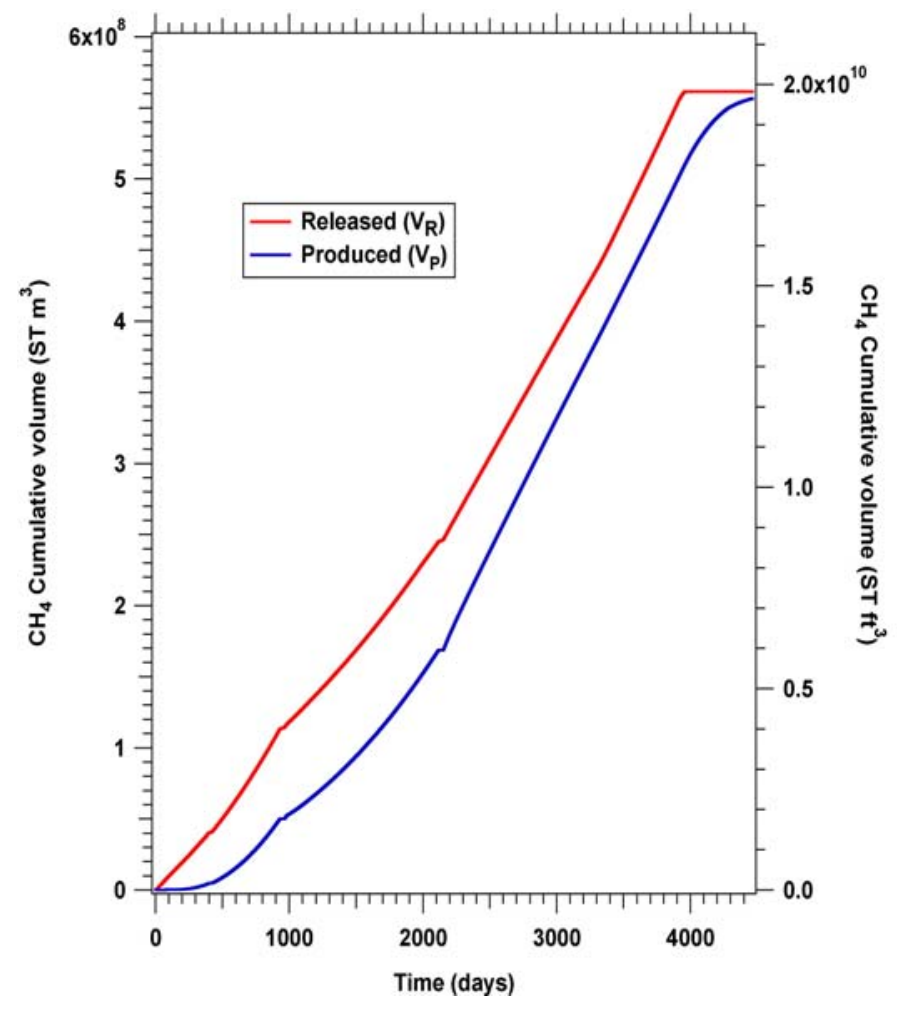

Figure 6 - Cumulative volumes of (a) hydrate-originating $\mathrm{CH}_{4}$ released in the reservoir $\left(V_{R}\right)$ and $(\mathrm{b})$ produced $\mathrm{CH}_{4}$ at the well $\left(V_{P}\right)$ during production from the Class 2 PA hydrate deposit in Case $A$. 

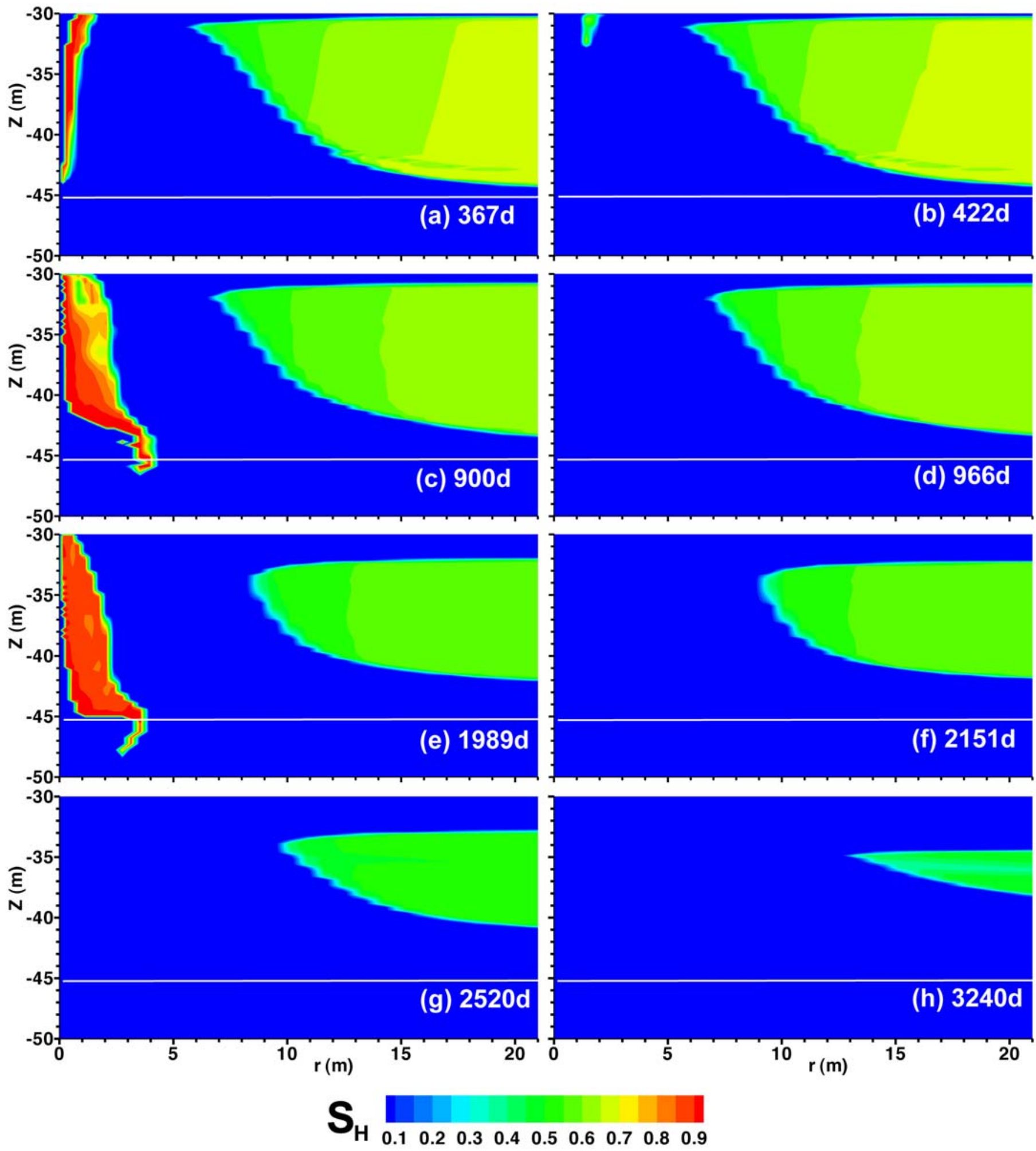

Figure 7 -Evolution of spatial distribution of $S_{H}$ during gas production from the Class 2 PA hydrate deposit in Case $B$. 

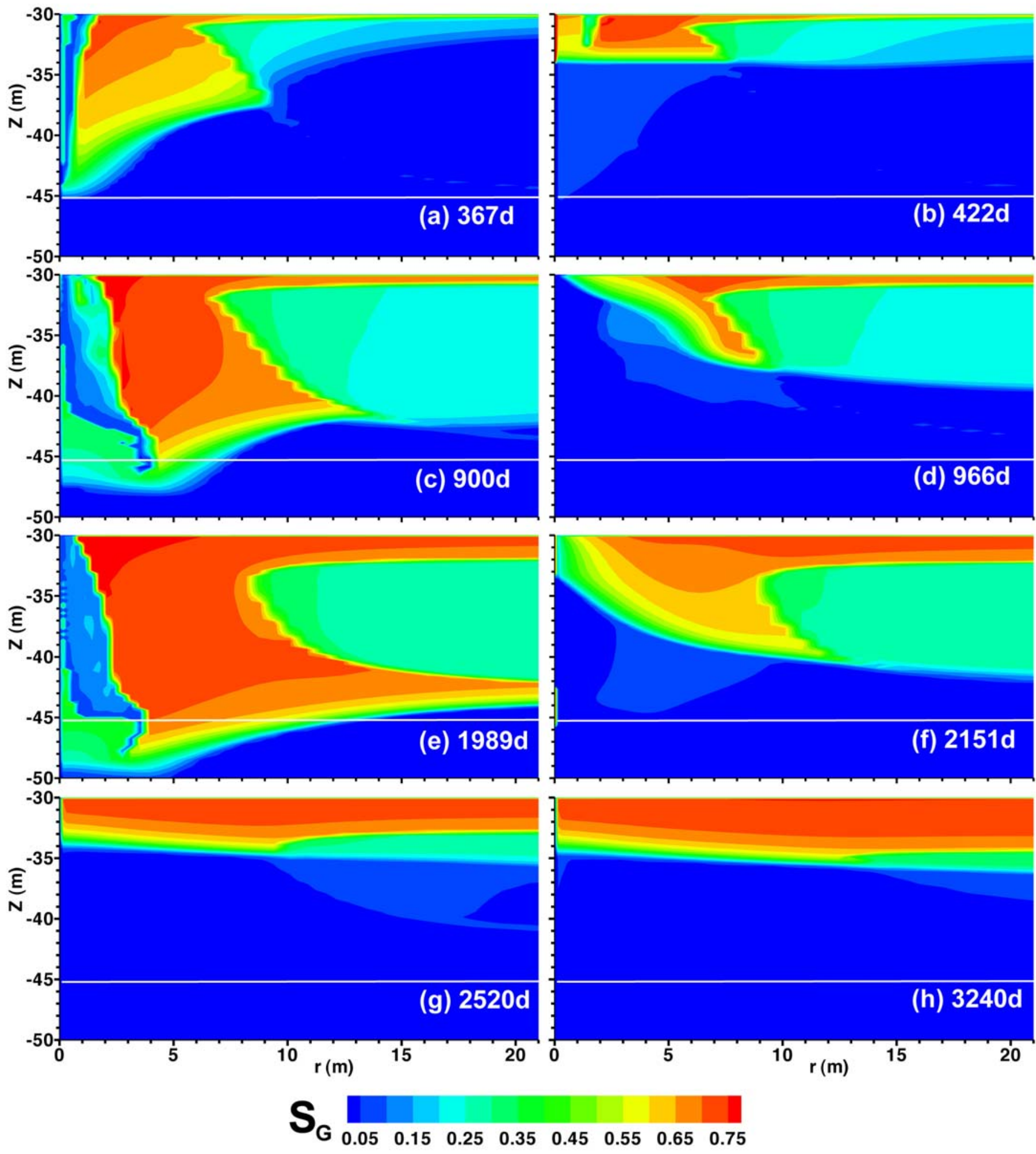

Figure 8 -Evolution of spatial distribution of $S_{G}$ during gas production from the Class 2 PA hydrate deposit in Case $B$. 

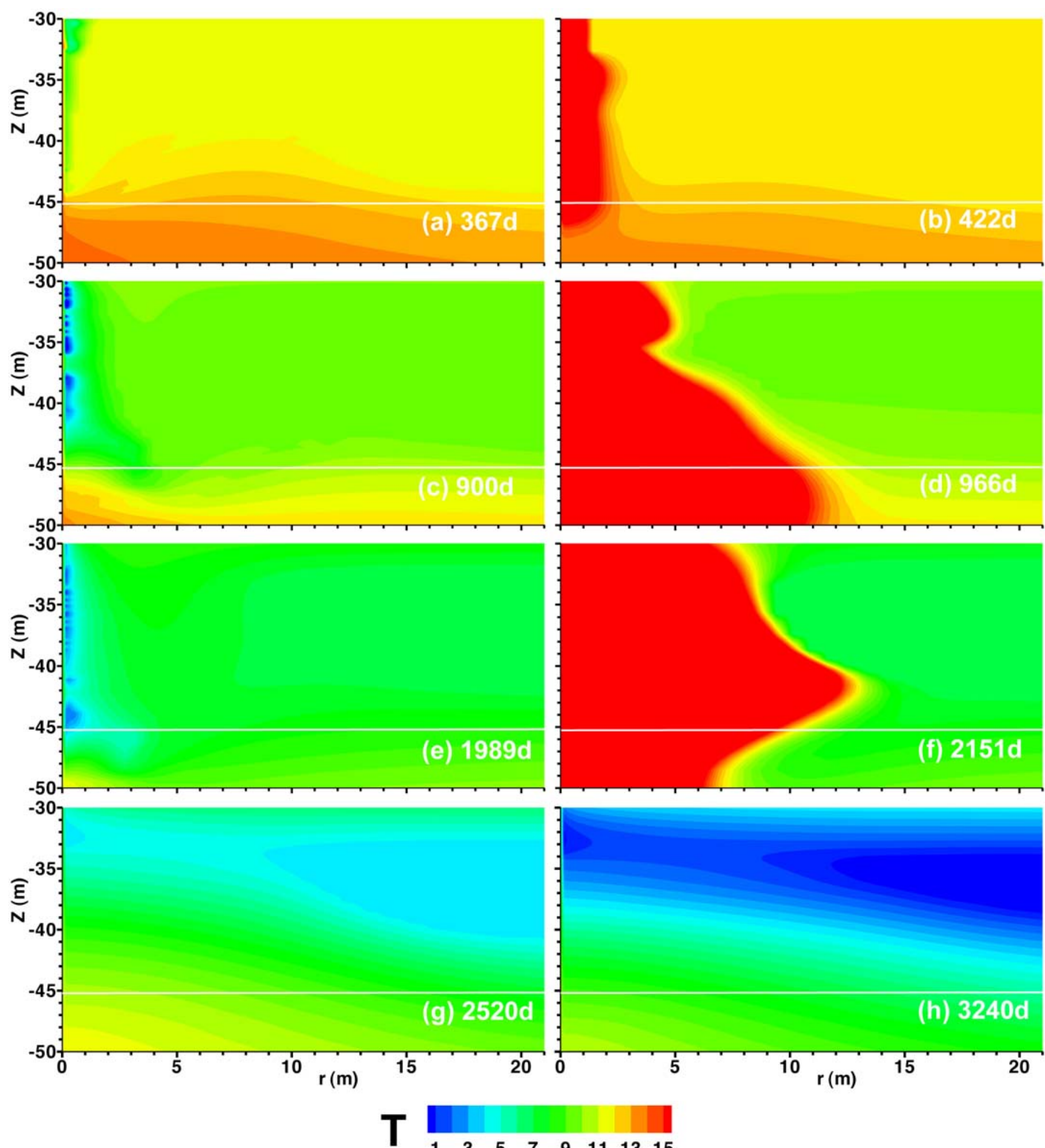

$\begin{array}{llllllll}1 & 3 & 5 & 7 & 9 & 11 & 13 & 15\end{array}$

Figure 9 -Evolution of spatial distribution of T during gas production from the Class 2 PA hydrate deposit in Case B. 


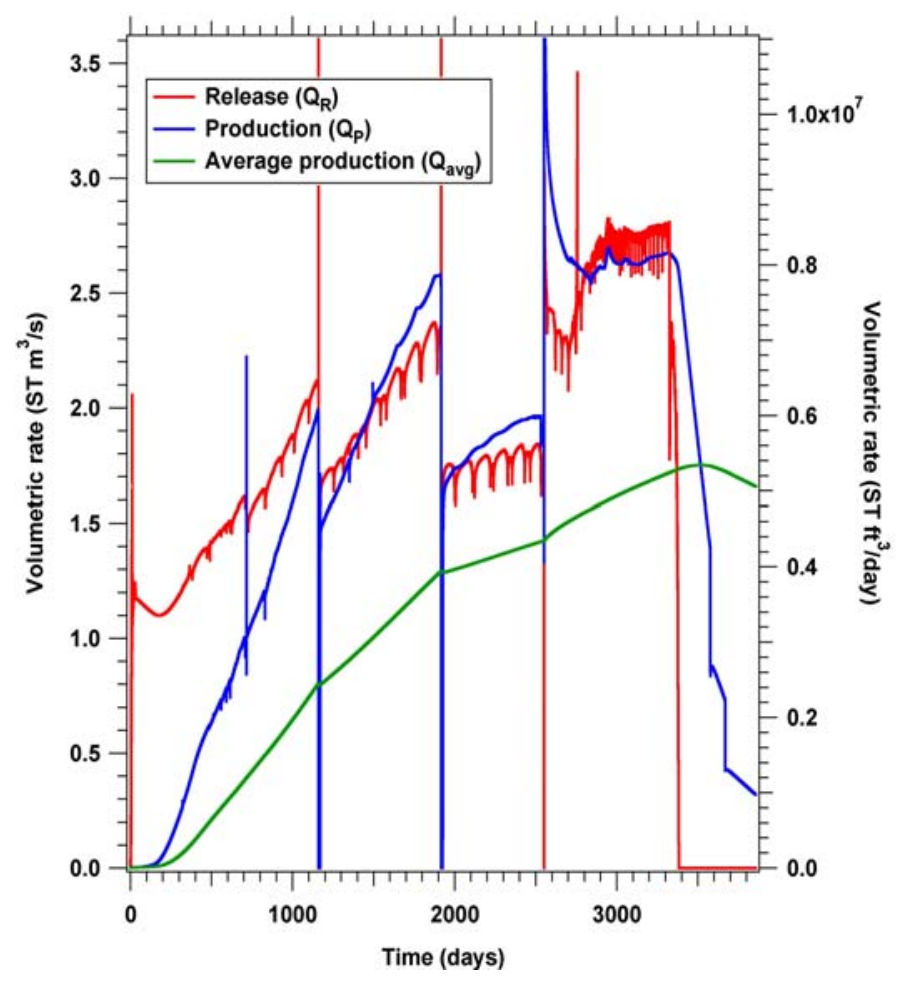

Figure 10 - Rates of (a) hydrate-originating $\mathrm{CH}_{4}$ release in the reservoir $\left(Q_{R}\right)$ and (b) $\mathrm{CH}_{4}$ production at the well $\left(Q_{P}\right)$ during production from the Class 2 PA hydrate deposit in Case $\mathrm{C}$. The evolution of the average gas production rate $\left(Q_{\text {avg }}\right)$ over the simulation period is also shown.

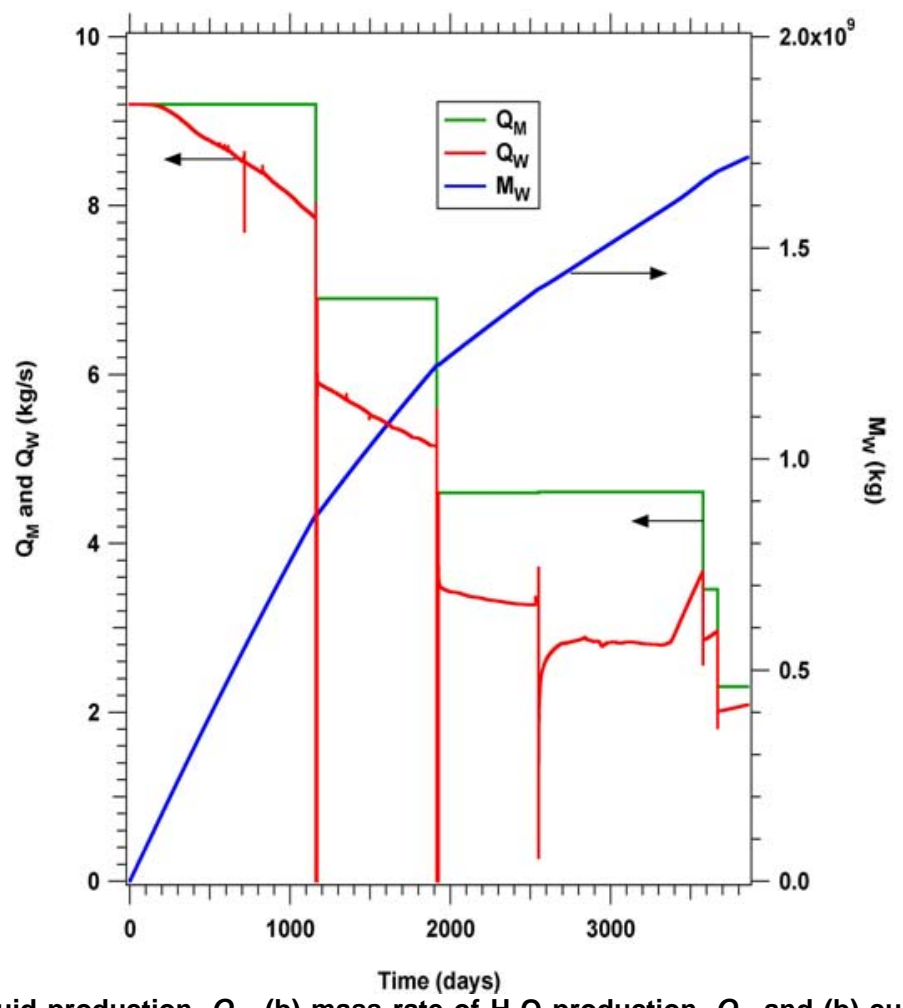

Figure 11 - (a) Mass rate of total fluid production, $Q_{M}$, (b) mass rate of $\mathrm{H}_{2} \mathrm{O}$ production, $Q_{w}$ and (b) cumulative mass of produced $\mathrm{H}_{2} \mathrm{O}$ ( $M_{W}$ ) during production from the Class 2 PA hydrate deposit in Case $\mathbf{C}$. 


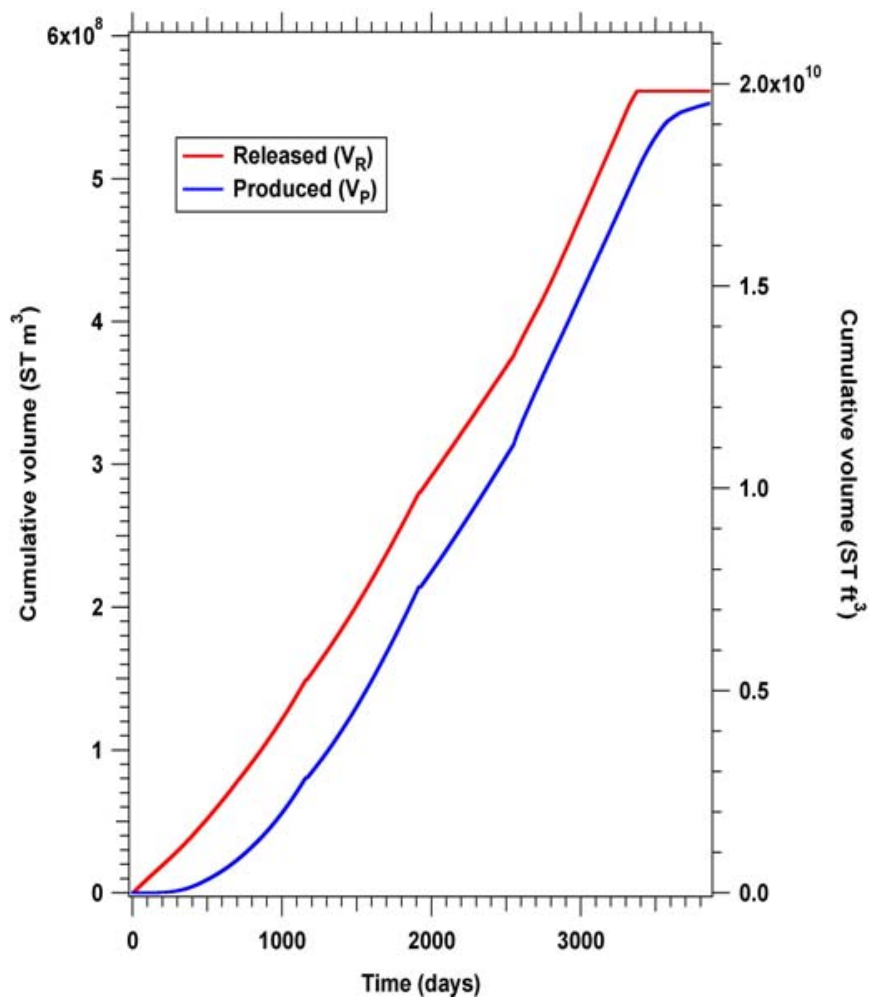

Figure 12 - Cumulative volumes of (a) hydrate-originating $\mathrm{CH}_{4}$ released in the reservoir $\left(V_{R}\right)$ and (b) produced $\mathrm{CH}_{4}$ at the well $\left(V_{P}\right)$ during production from the Class 2 PA hydrate deposit in Case $C$. 


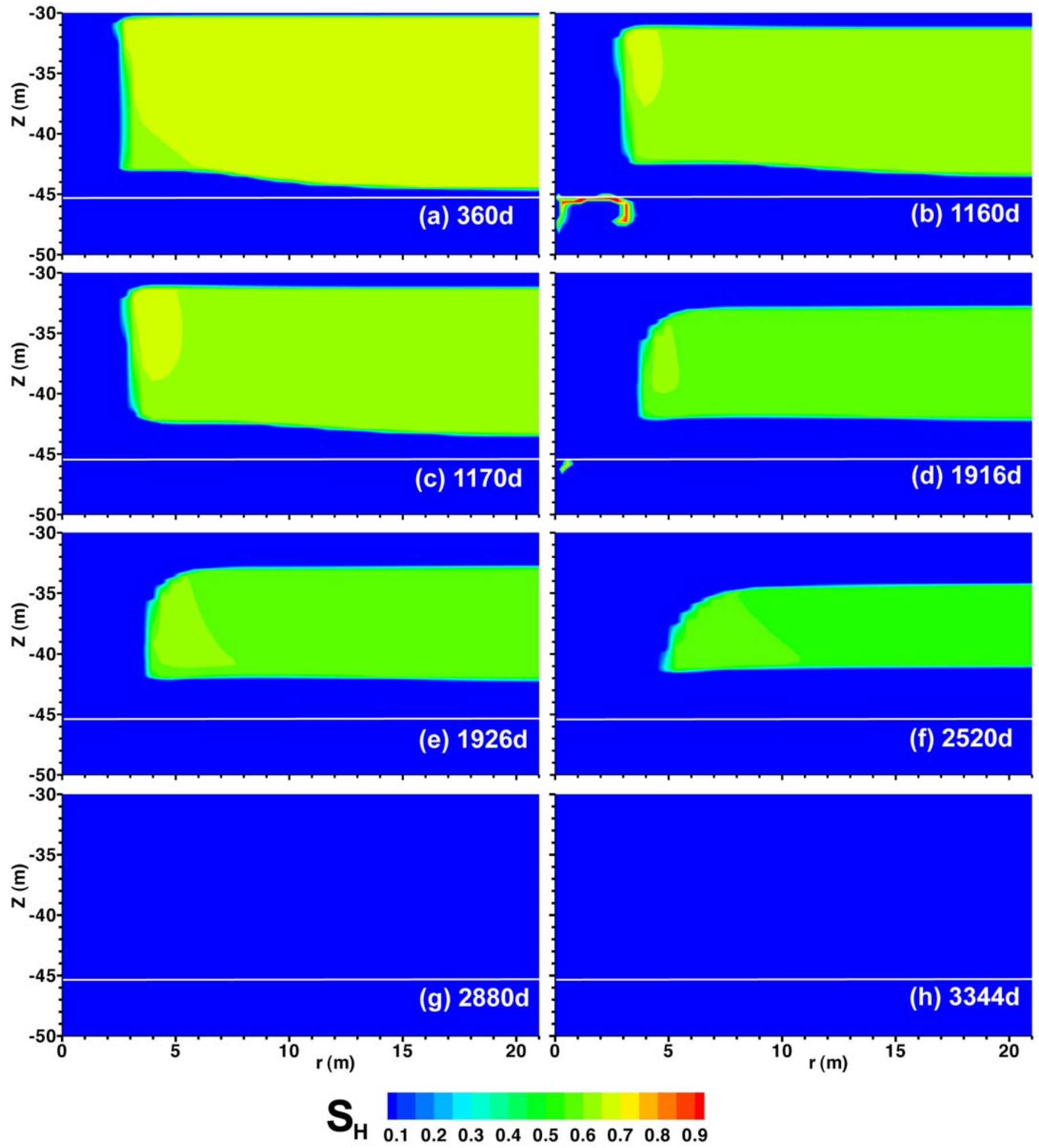

Figure 13 -Evolution of spatial distribution of $S_{H}$ during gas production from the Class 2 PA hydrate deposit in Case $C$. 

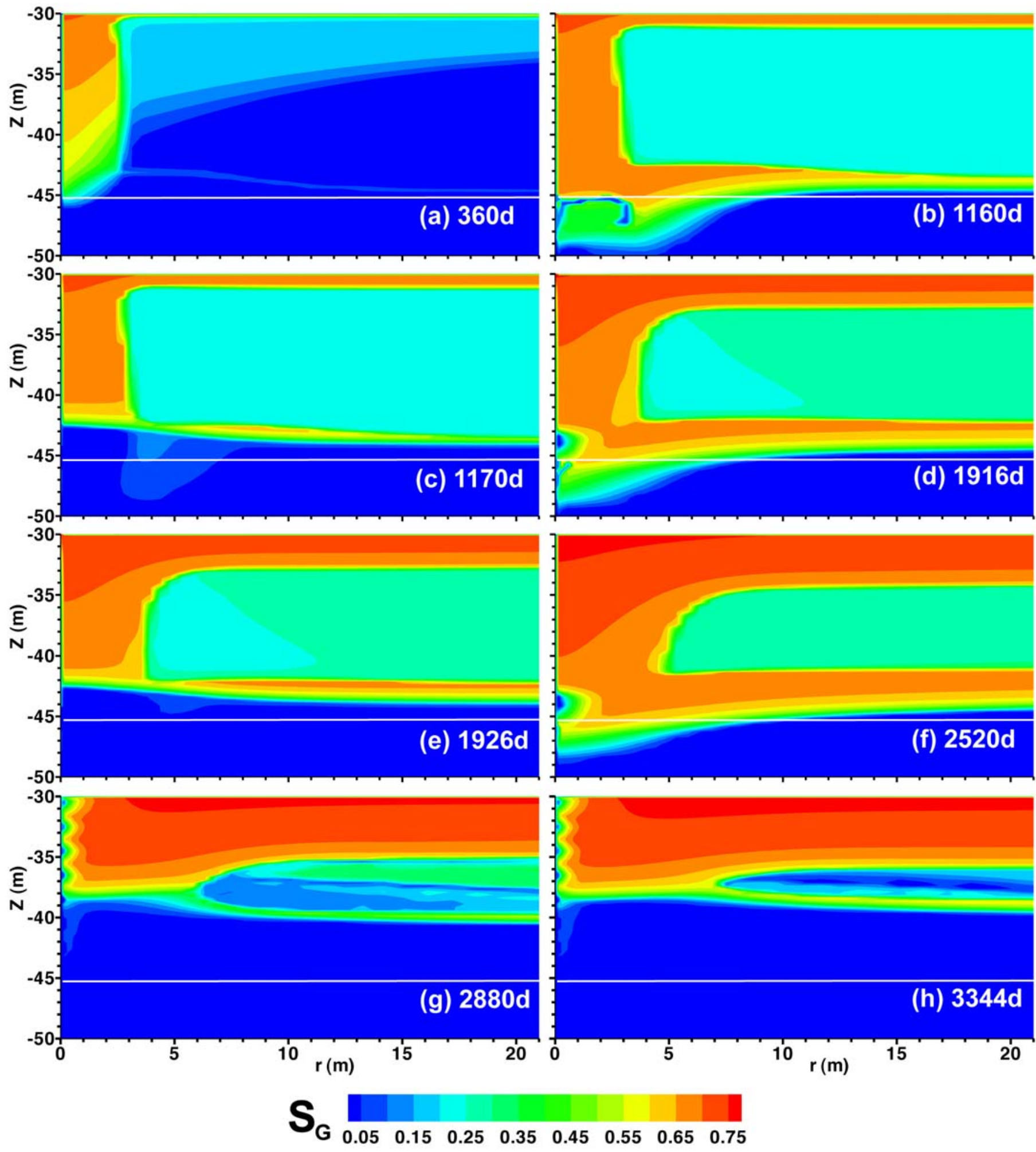

Figure 14 -Evolution of spatial distribution of $S_{G}$ during gas production from the Class 2 PA hydrate deposit in Case $C$. 


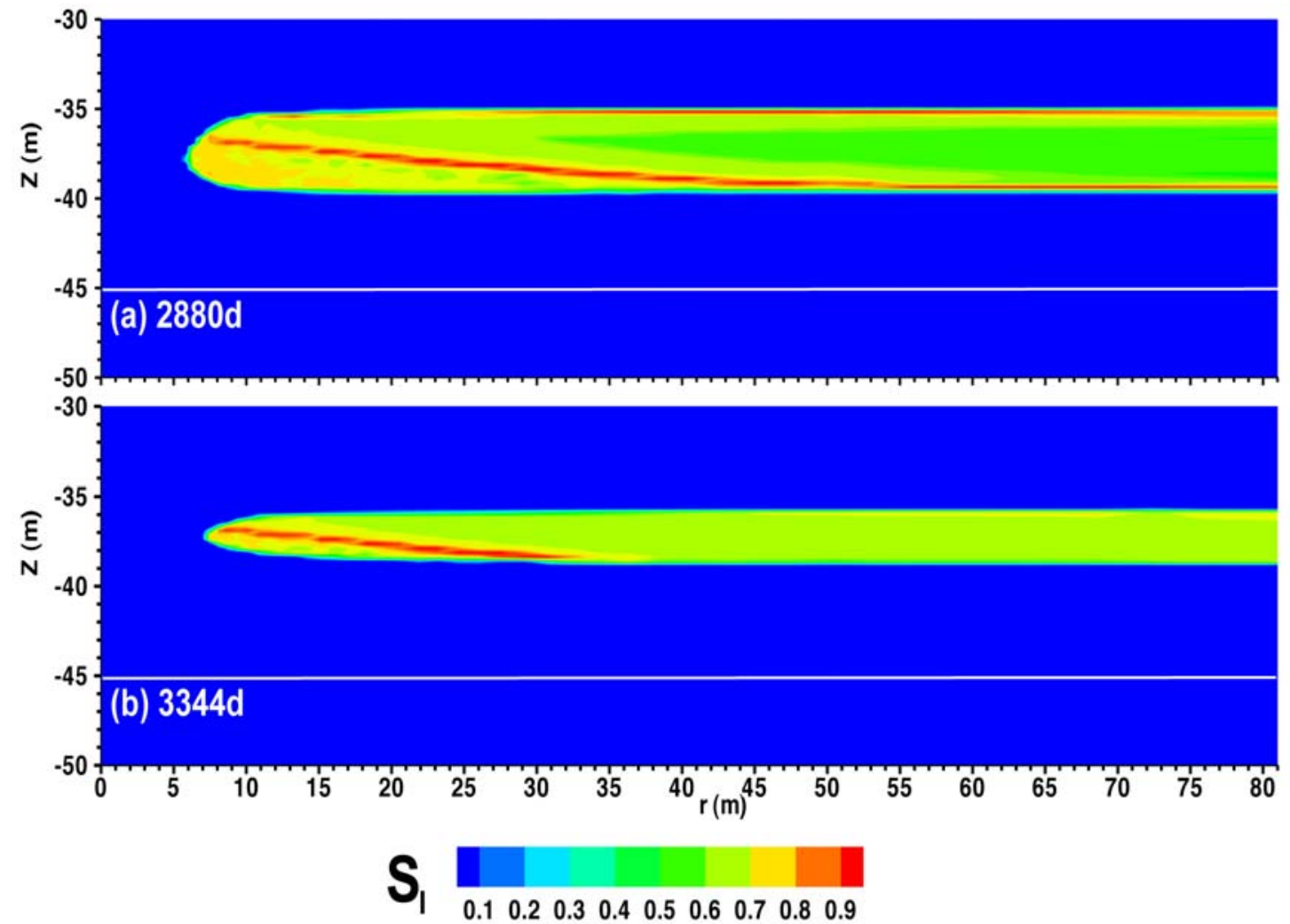

Figure 15 -Evolution of spatial distribution of $S_{1}$ during gas production from the Class 2 PA hydrate deposit in Case $C$. 


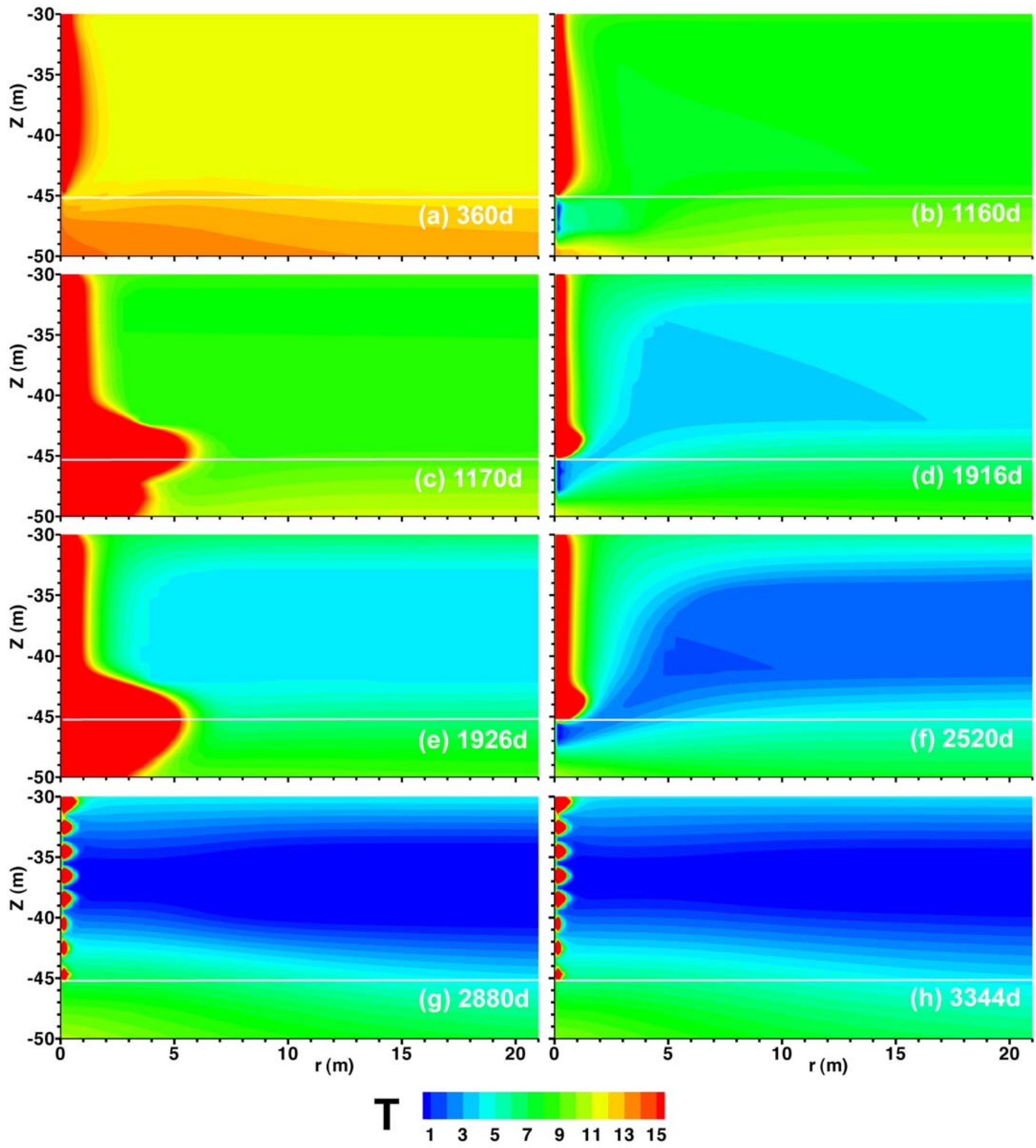

Figure 16 -Evolution of spatial distribution of T during gas production from the Class 2 PA hydrate deposit in Case C. 


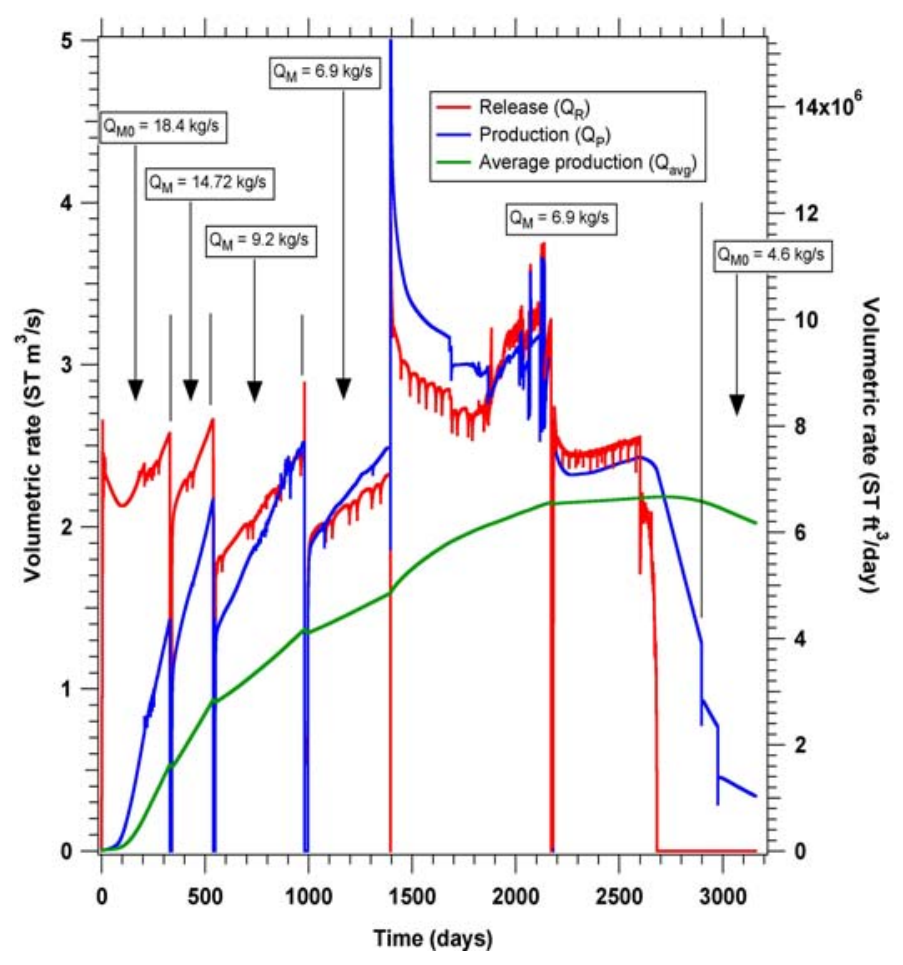

Figure 17 - Evolution of $Q_{R}$ and $Q_{P}$ during production from the Class 2 PA hydrate deposit in Case C for $Q_{M 0}=2 Q_{M 0, \text { ref. }}$ The evolution of $Q_{M}$ and $Q_{\text {avg }}$ over the simulation period are also shown.

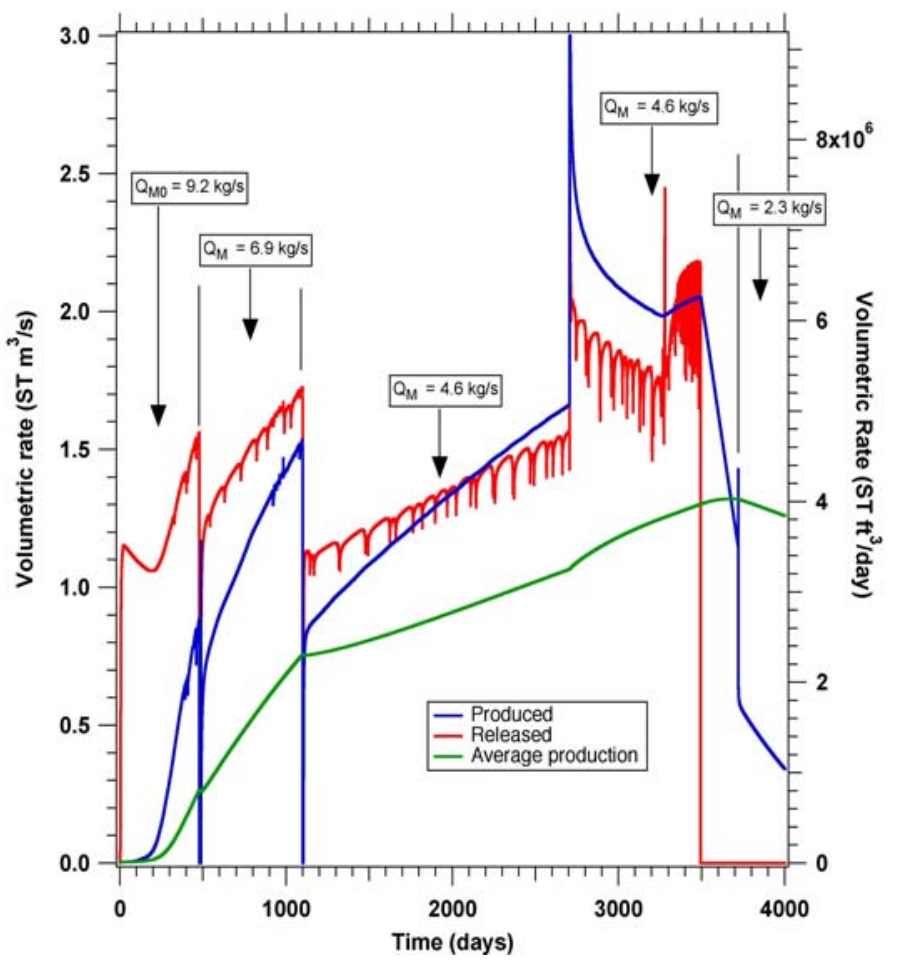

Figure $18-Q_{R}$ and $Q_{P}$ during production from the Class 2 PA hydrate deposit in Case C when $S_{H}=0.55\left(Q_{H o}=9.2 \mathrm{~kg} / \mathrm{s}\right)$. The average production rate $\left(Q_{\text {avg }}\right)$ over the simulation period is also shown. 


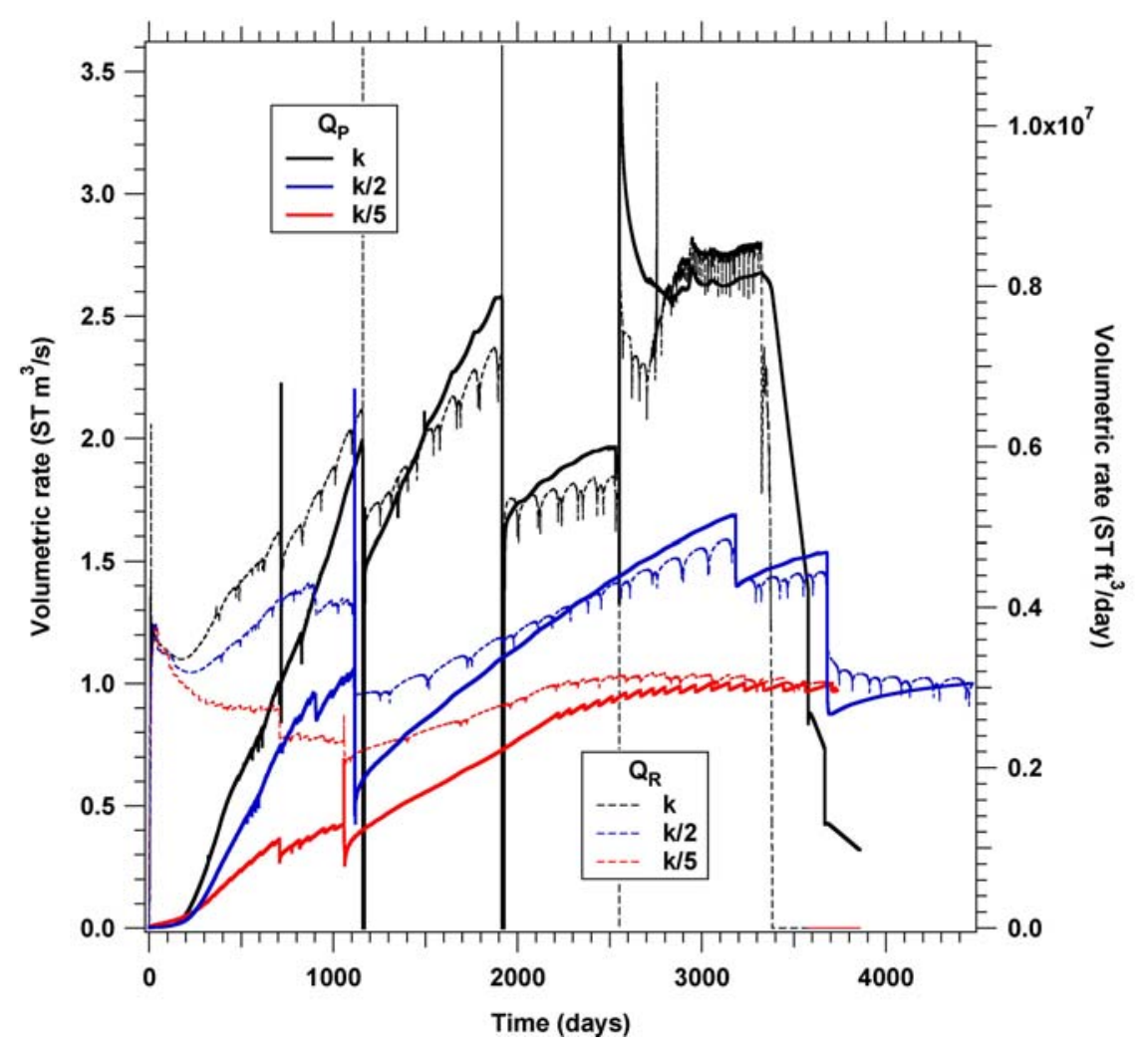

Figure 19 - Effect of $k$ on $Q_{R}$ and $Q_{P}$ during production from the Class 2 PA hydrate deposit in Case C $\left(Q_{H_{0}}=9.2 \mathrm{~kg} / \mathrm{s}\right)$.

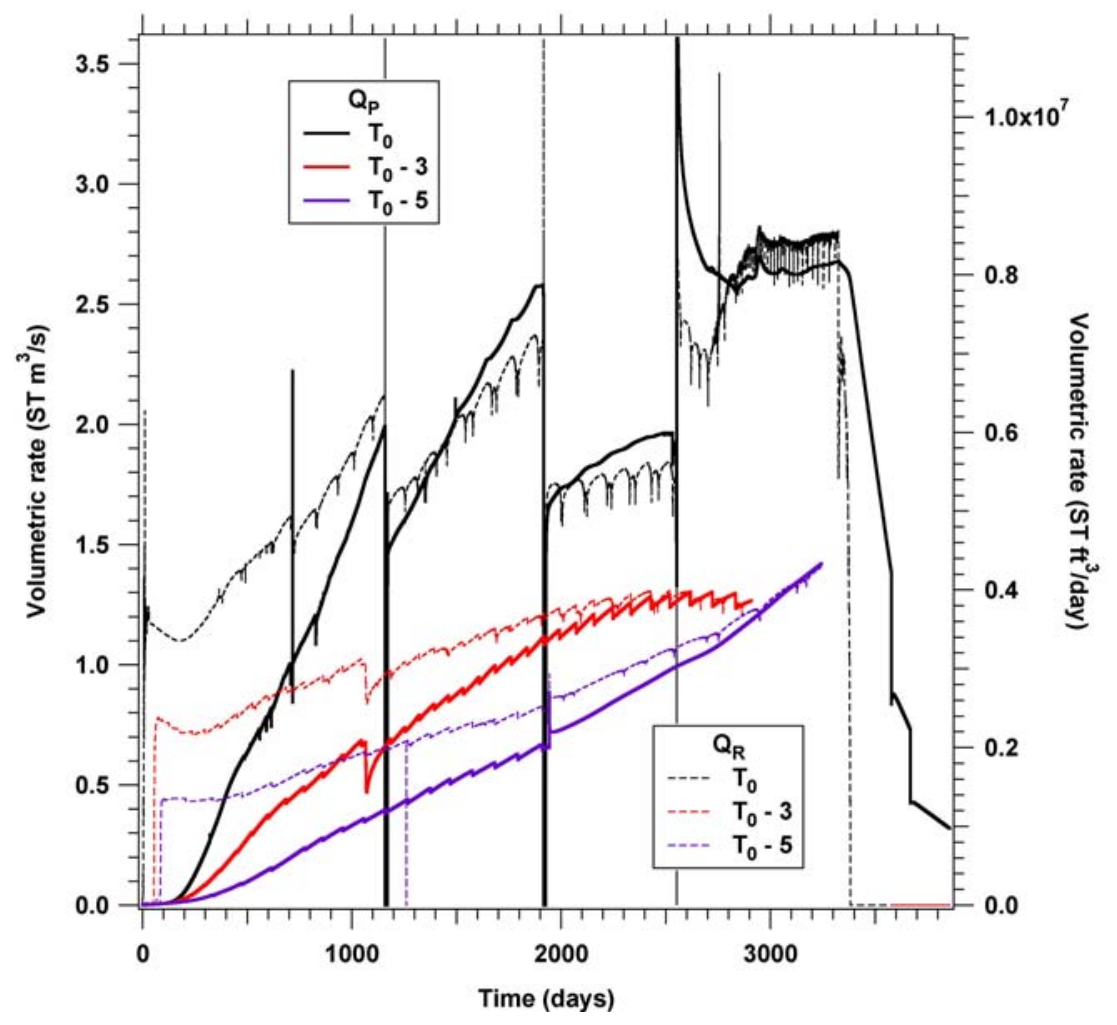

Figure 20 - Effect of $T_{0}$ on $Q_{R}$ and $Q_{P}$ during production from the Class 2 PA hydrate deposit in Case C $\left(Q_{H O}=9.2 \mathrm{~kg} / \mathrm{s}\right)$. 


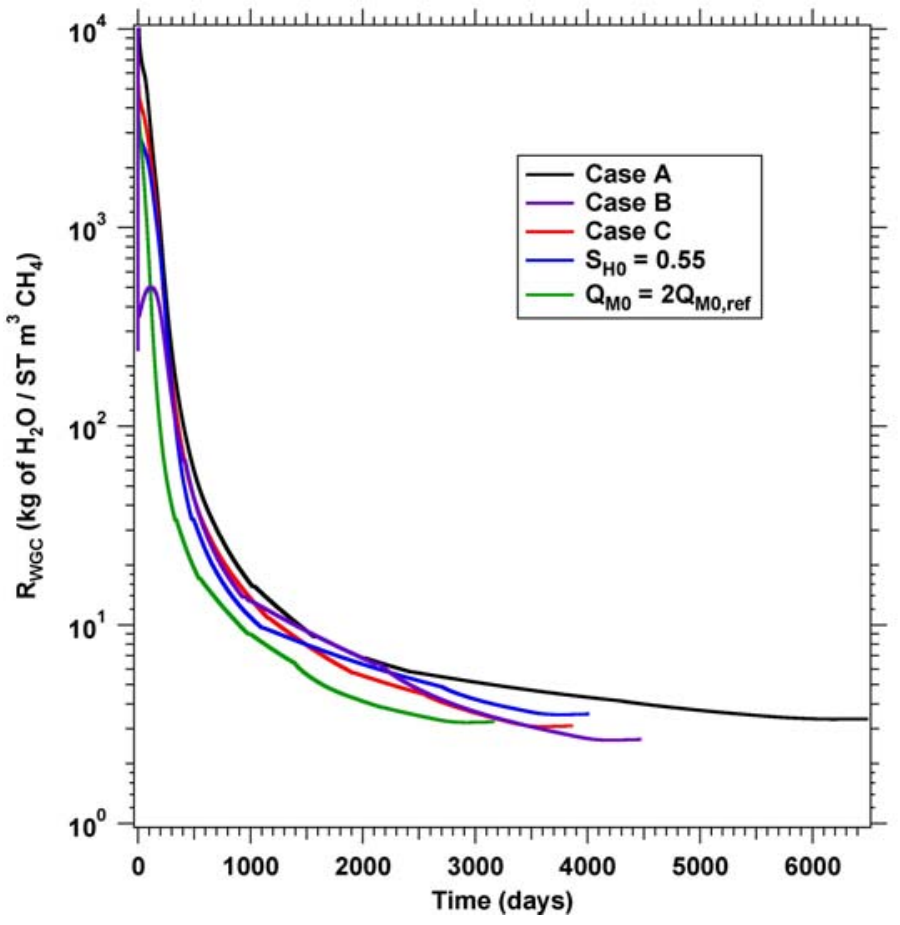

Figure 21 - Evolution of the water-to-gas ratio $\left(R_{W G C}\right)$ over time during gas production from the PA hydrate deposit in this study. Note the continuous and monotonic decline of $\boldsymbol{R}_{W G C}$ until the time of the hydrate exhaustion. 


\section{DISCLAIMER}

This document was prepared as an account of work sponsored by the United States Government. While this document is believed to contain correct information, neither the United States Government nor any agency thereof, nor The Regents of the University of California, nor any of their employees, makes any warranty, express or implied, or assumes any legal responsibility for the accuracy, completeness, or usefulness of any information, apparatus, product, or process disclosed, or represents that its use would not infringe privately owned rights. Reference herein to any specific commercial product, process, or service by its trade name, trademark, manufacturer, or otherwise, does not necessarily constitute or imply its endorsement, recommendation, or favoring by the United States Government or any agency thereof, or The Regents of the University of California. The views and opinions of authors expressed herein do not necessarily state or reflect those of the United States Government or any agency thereof or The Regents of the University of California.

Ernest Orlando Lawrence Berkeley National Laboratory is an equal opportunity employer. 